\title{
Derivatization of Amino Acids and Peptides via Photoredox- mediated Conjugate Addition
}

\author{
Olivia Zhang and Jeffrey Schubert* \\ jeffrey_schubert@merck.com \\ Department of Discovery Chemistry, MRL, Merck \& Co., Inc., \\ 770 Sumneytown Pike, West Point, Pennsylvania 19486 USA
}

- Schemes S1 and S2

$\mathrm{S}-2$

- ${ }^{1} \mathrm{H}$ NMR, ${ }^{13} \mathrm{C}$ NMR spectra of all compounds

S-3 
Scheme $\mathrm{S} 1^{1}$

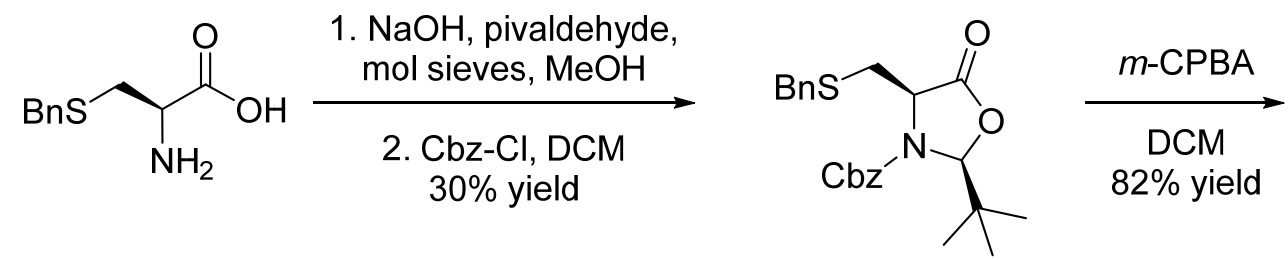<smiles>CC(C)([18O])[C@@H]1OC(=O)[C@@H](CS(=O)(=O)OCc2ccccc2)N1C(=O)OCc1ccccc1</smiles>

1-2<smiles>C=C1C(=O)OC(C(C)(C)C)N1C(=O)OCc1ccccc1</smiles>

1

Scheme S2

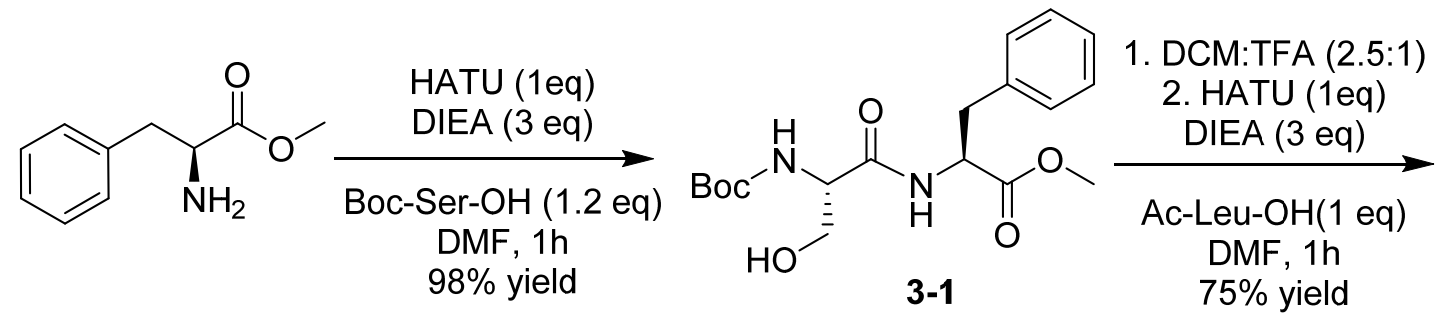<smiles>COC(=O)[C@H](Cc1ccccc1)NC(=O)[C@H](CO)NC(=O)[C@H](CC(C)C)NC(C)=O</smiles>

3-2
1-1
3-1<smiles>C=C(NC(=O)[C@H](CC(C)C)NC(C)=O)C(=O)N[C@@H](Cc1ccccc1)C(=O)OC</smiles>

${ }^{1}$ ACS Catalysis 2018, 8 (10), 9115-9119. 


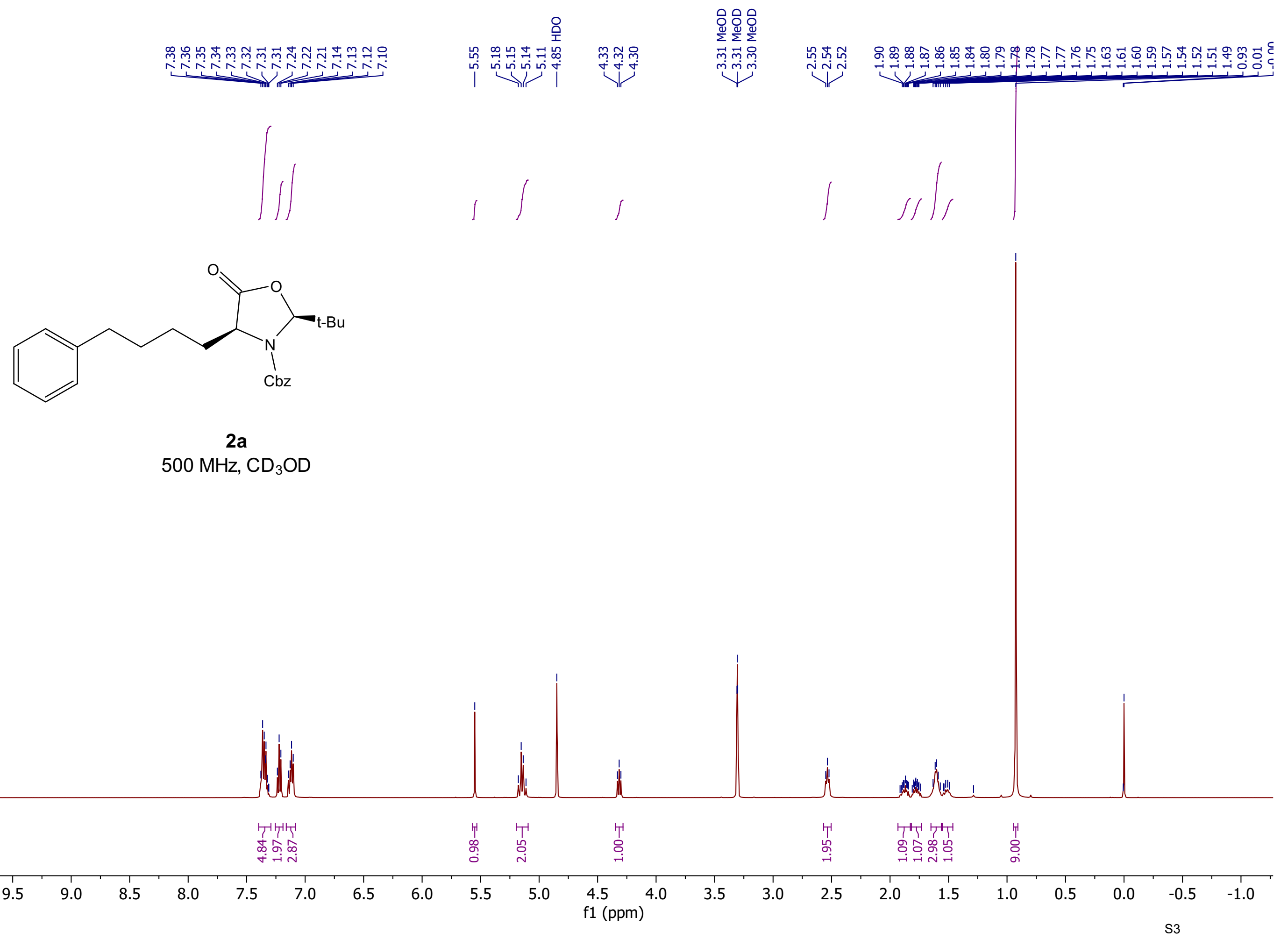




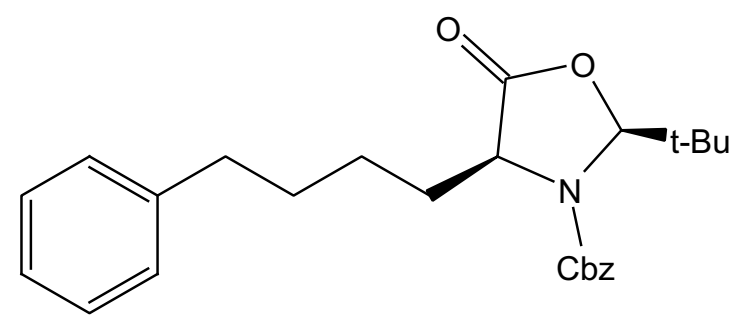

$2 a$

$126 \mathrm{MHz}, \mathrm{CD}_{3} \mathrm{OD}$

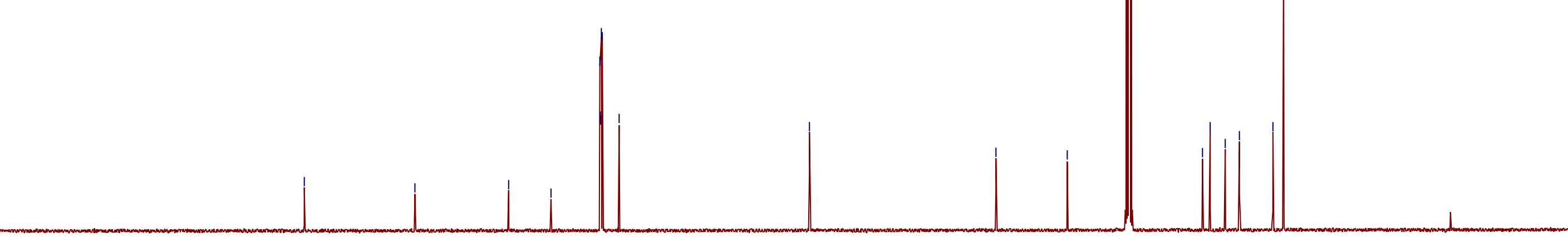


$1 / 1$

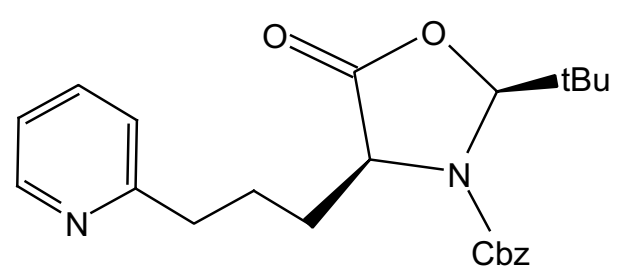

2b

$500 \mathrm{MHz}, \mathrm{CD}_{3} \mathrm{OD}$

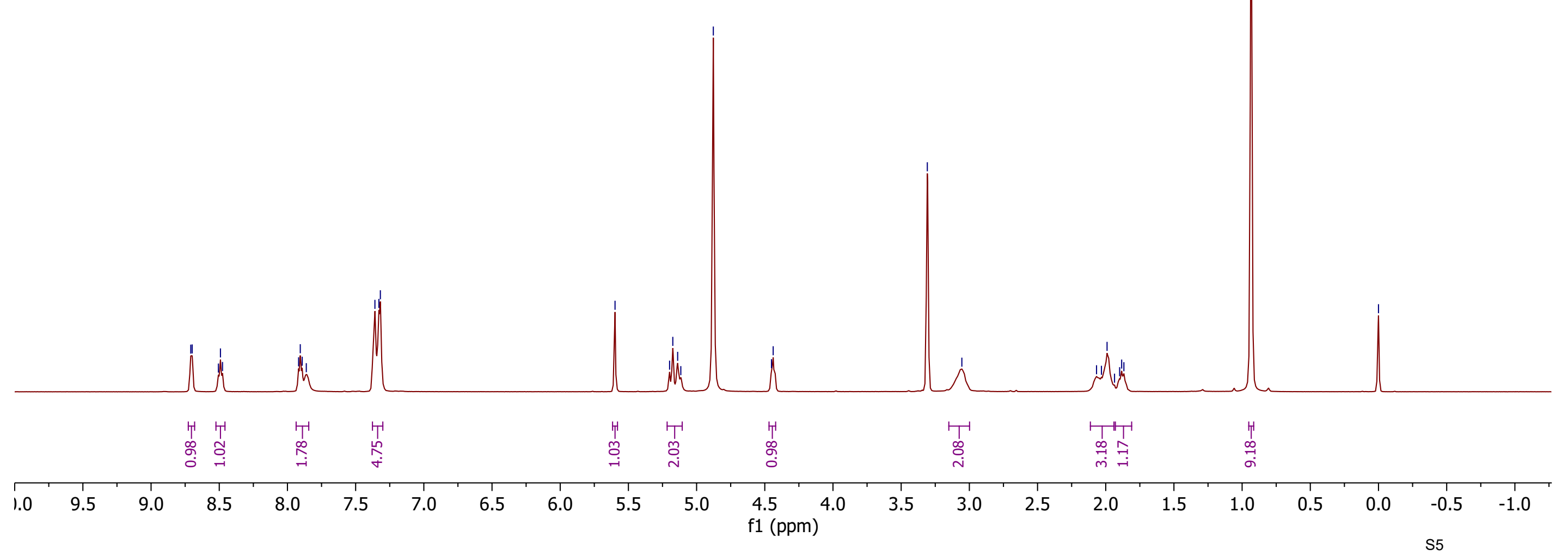




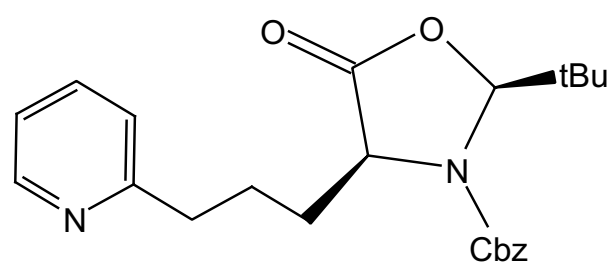

2b

$126 \mathrm{MHz}, \mathrm{CD}_{3} \mathrm{OD}$ 


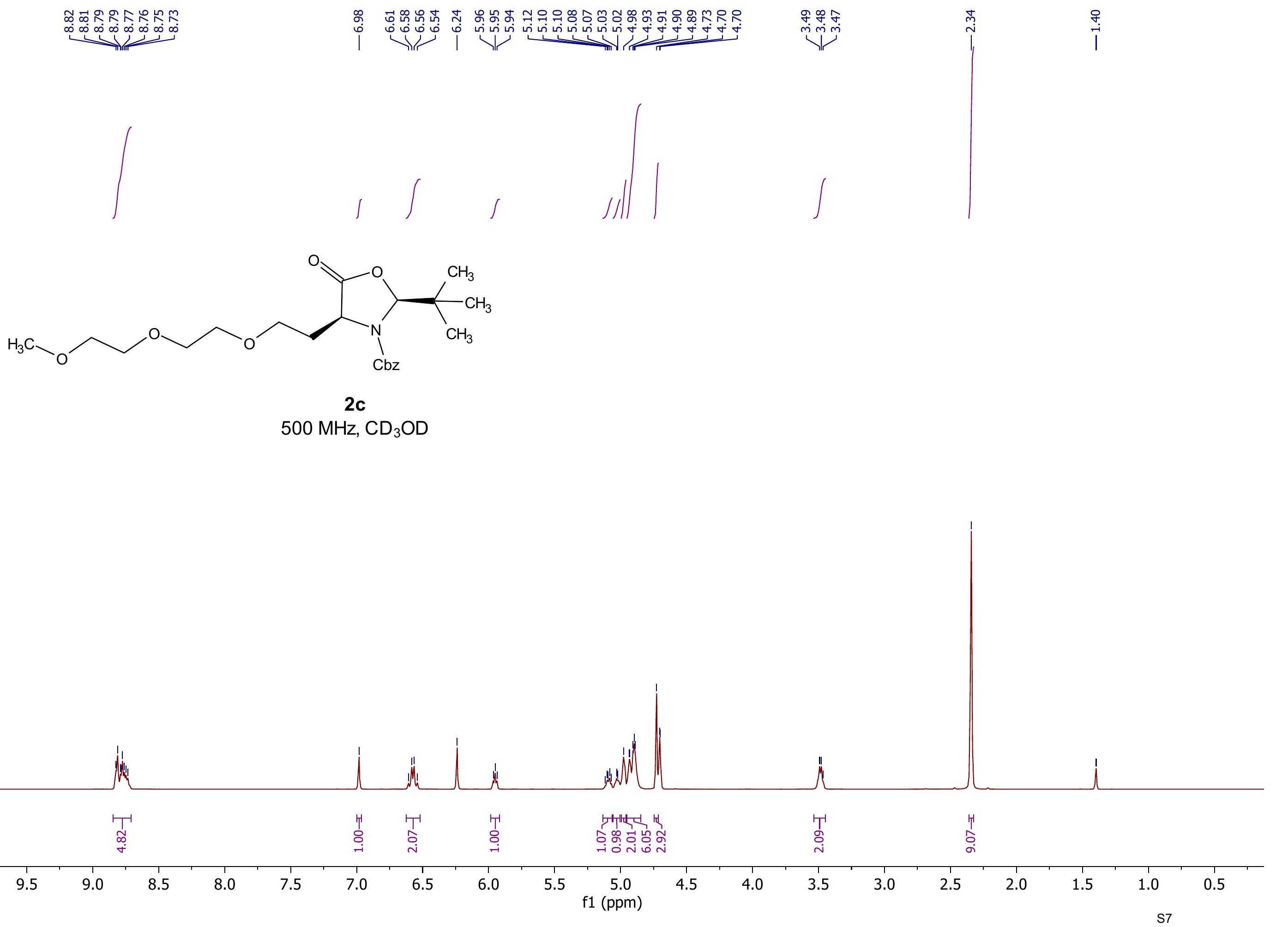




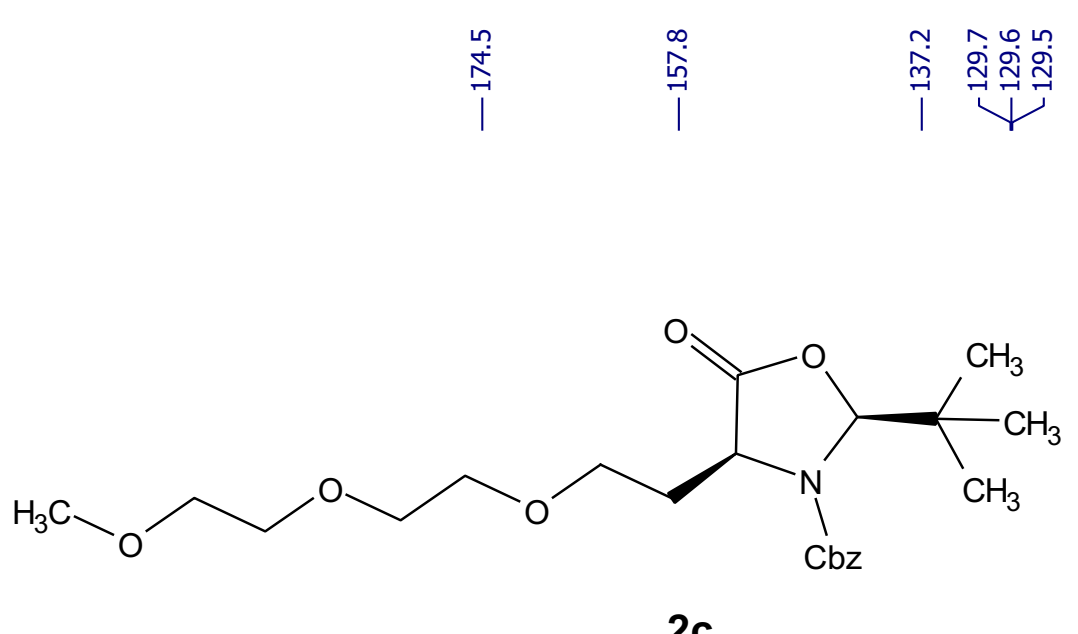

$126 \mathrm{MHz}, \mathrm{CD}_{3} \mathrm{OD}$ 


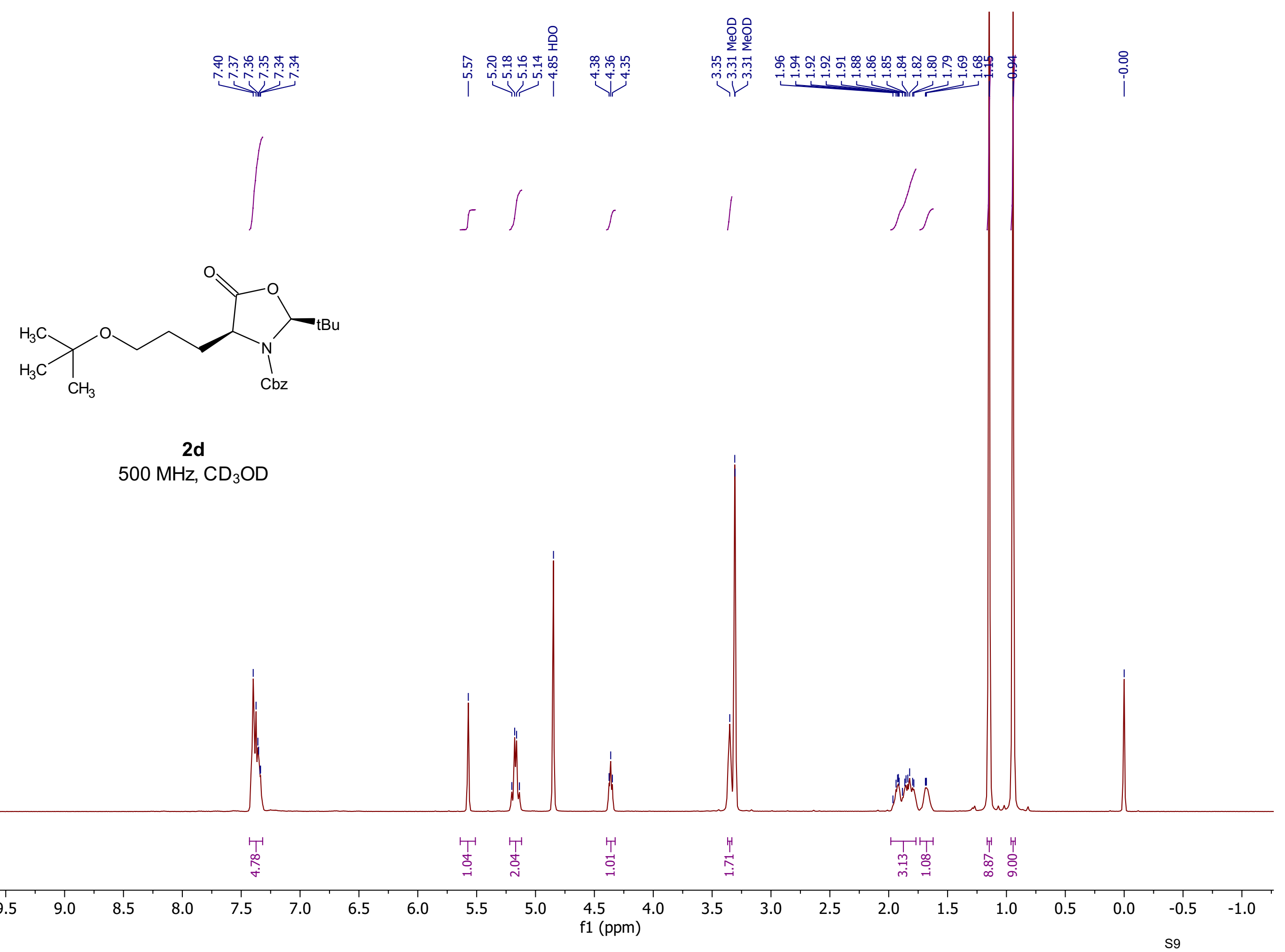




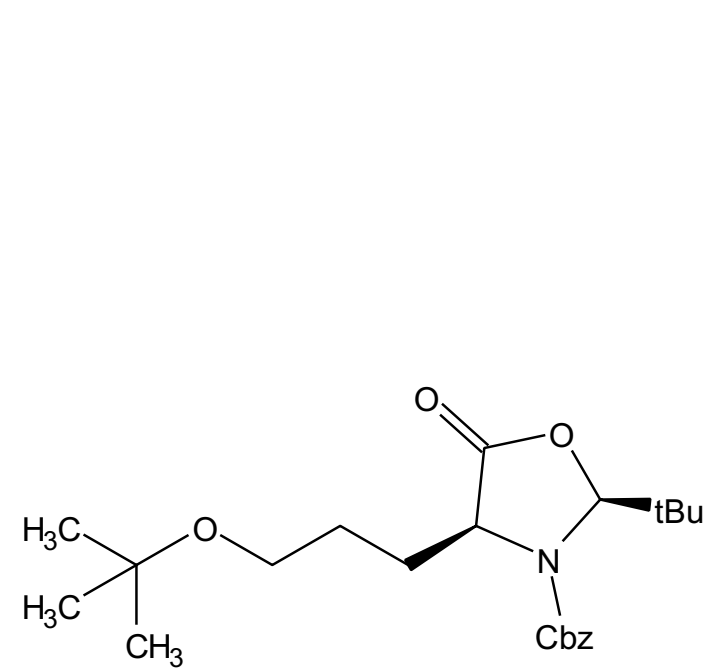

$2 d$

$126 \mathrm{MHz}, \mathrm{CD}_{3} \mathrm{OD}$ 


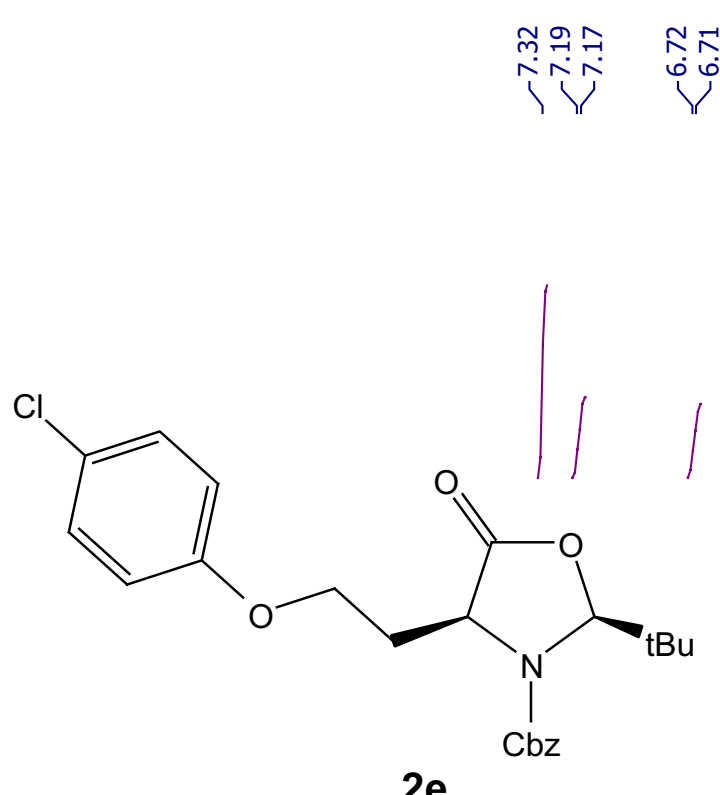

$500 \mathrm{MHz}, \mathrm{CD}_{3} \mathrm{OD}$
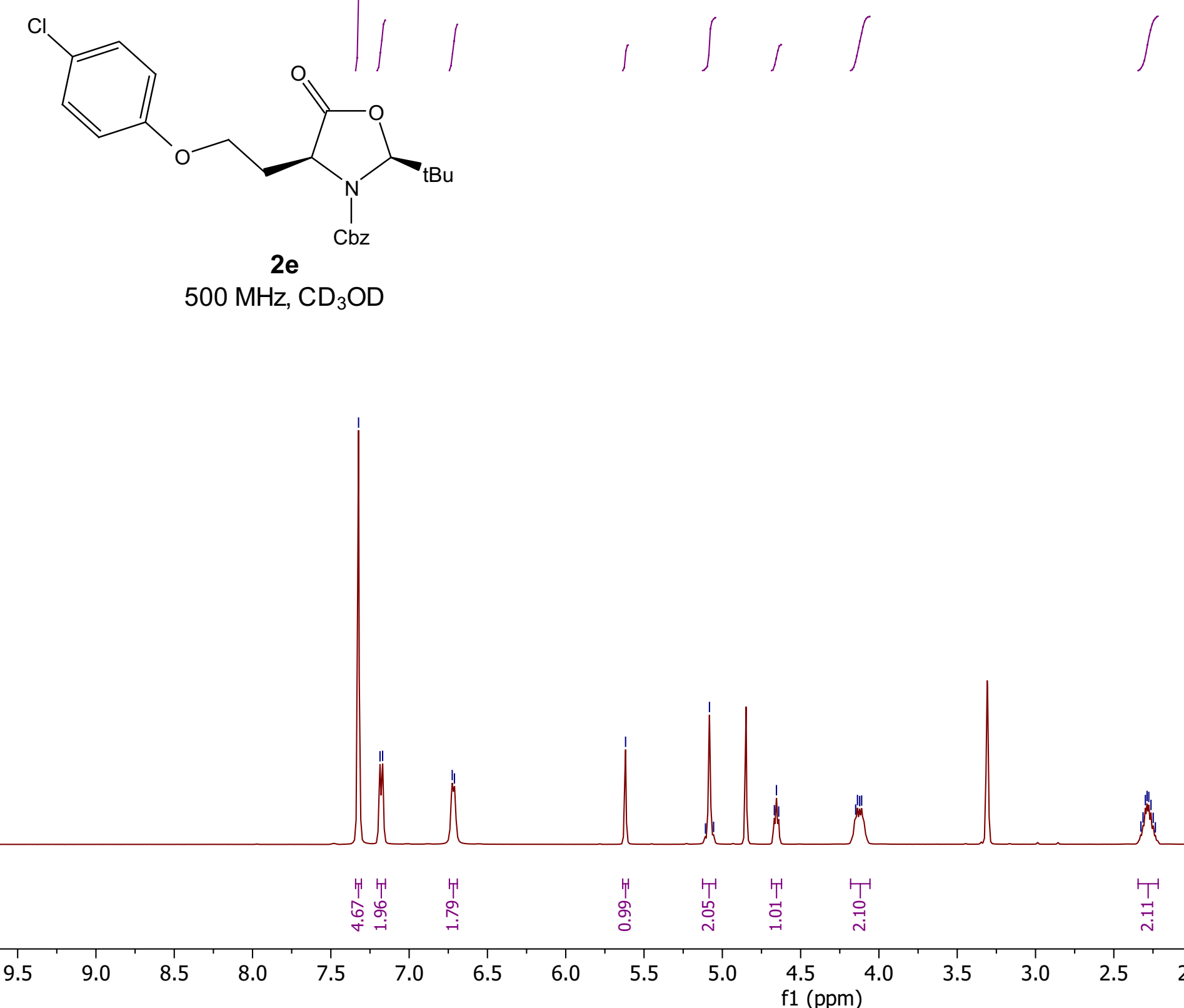

\begin{tabular}{|c|c|}
\hline 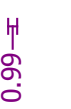 & $\begin{array}{l}\text { Th } \\
\text { 岁 } \\
\text { in }\end{array}$ \\
\hline 5.5 & 5.0 \\
\hline
\end{tabular}

$4.5{ }^{4} 4.0$
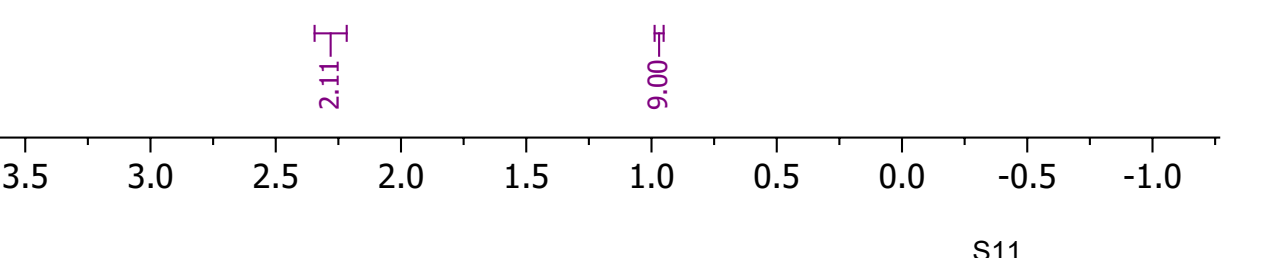


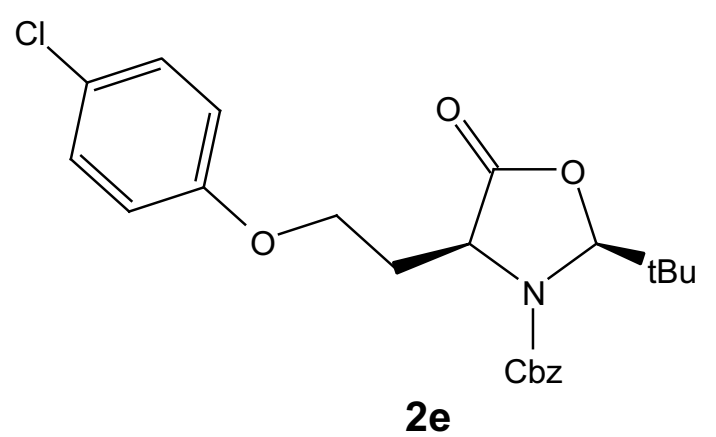

$126 \mathrm{MHz}, \mathrm{CD}_{3} \mathrm{OD}$ 

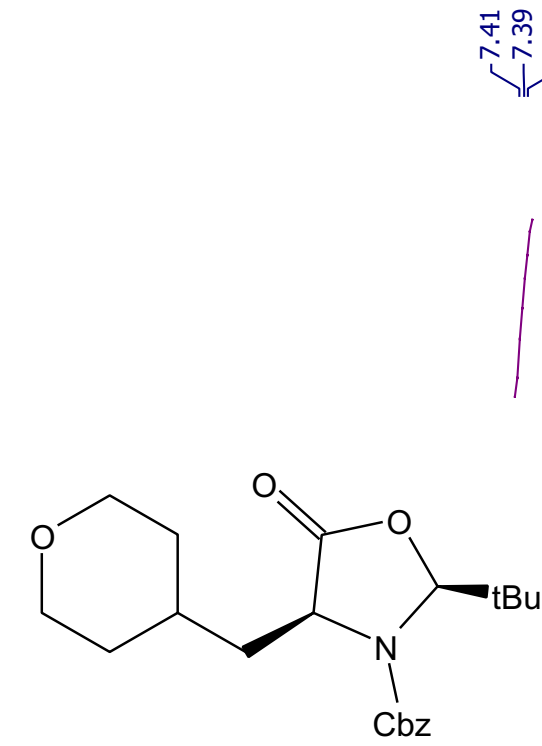

$2 f$

$500 \mathrm{MHz}, \mathrm{CD}_{3} \mathrm{OD}$

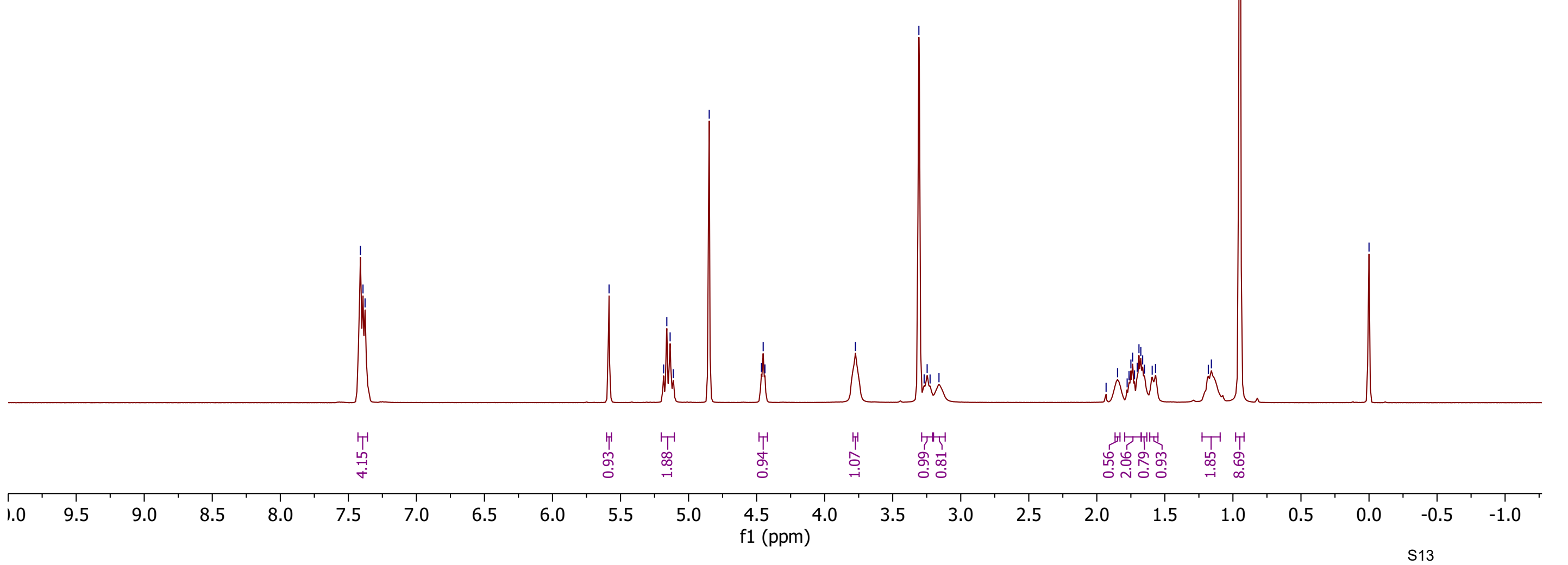




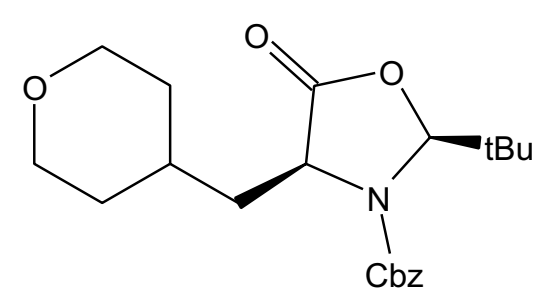

$2 f$

$126 \mathrm{MHz}, \mathrm{CD}_{3} \mathrm{OD}$ 

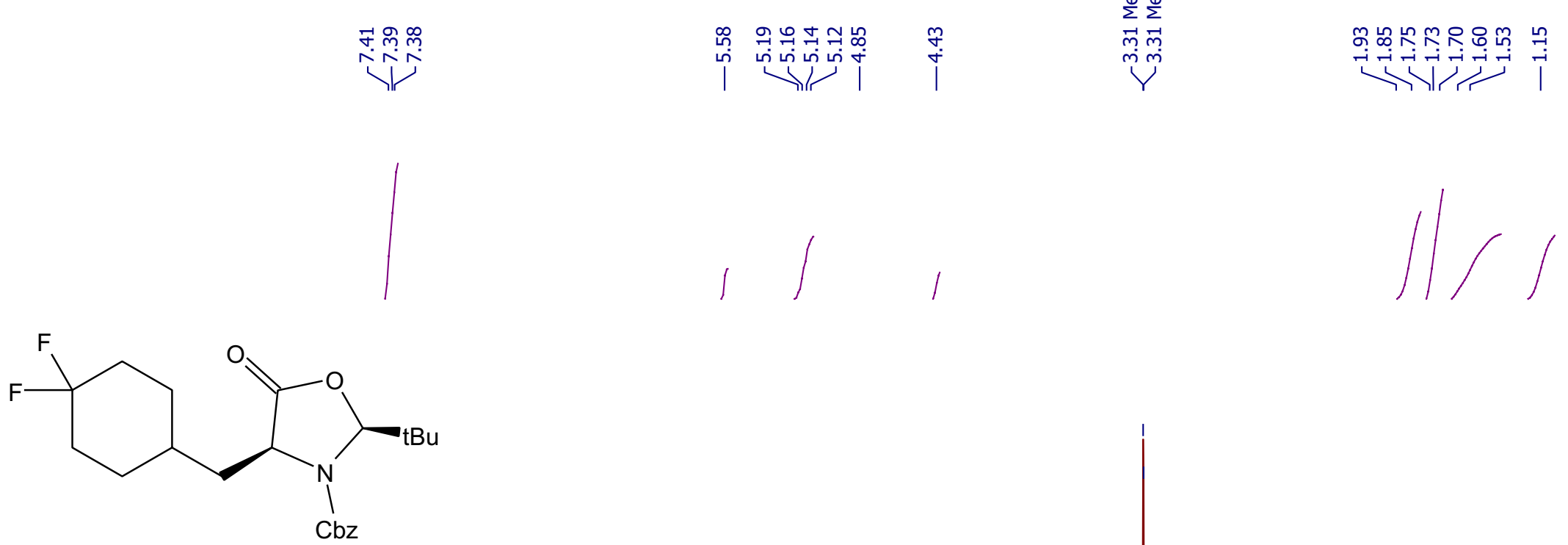

$2 \mathrm{~g}$

$500 \mathrm{MHz}, \mathrm{CD}_{3} \mathrm{OD}$
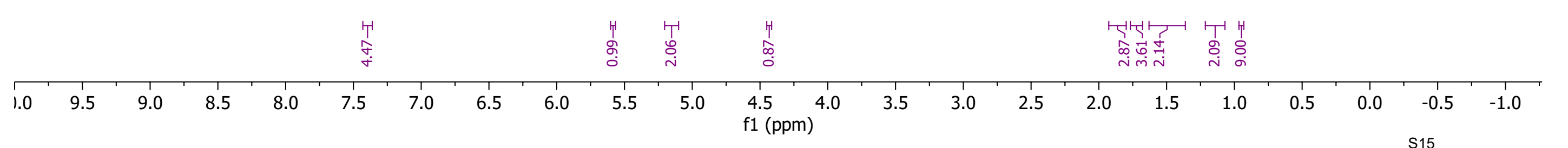


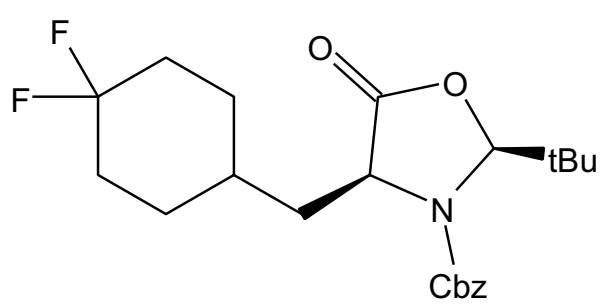

$2 \mathrm{~g}$

$126 \mathrm{MHz}, \mathrm{CD}_{3} \mathrm{OD}$ 
<smiles>CCC</smiles><smiles>CC(C)(C)CC1OC(=O)[C@@H](CC2CC(C)(C)C2)N1C(=O)OCc1ccccc1</smiles>

2h

$500 \mathrm{MHz}, \mathrm{CD}_{3} \mathrm{OD}$

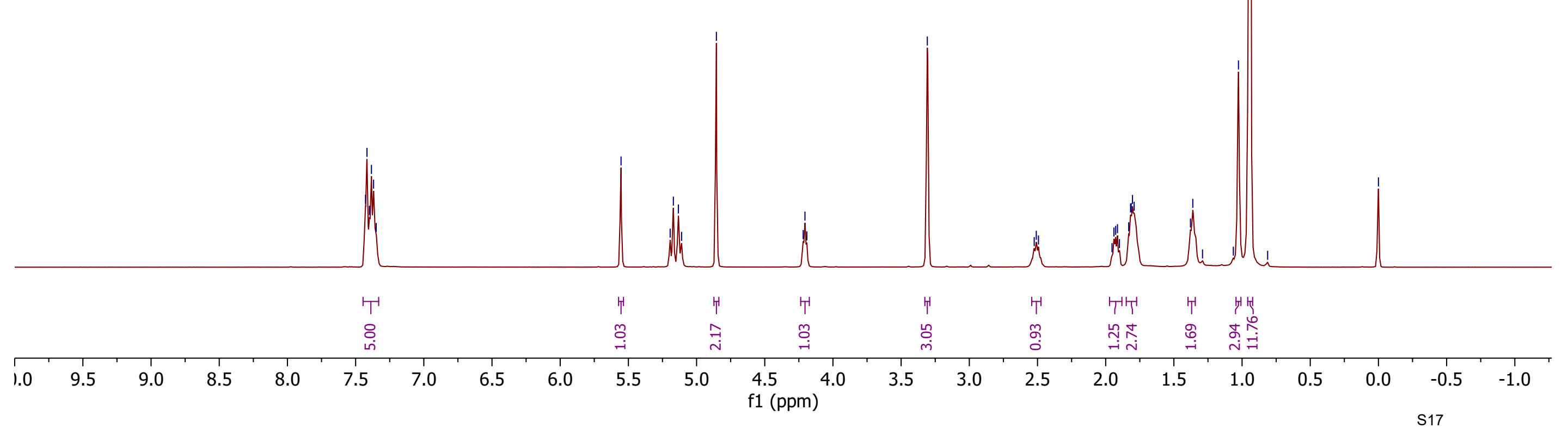




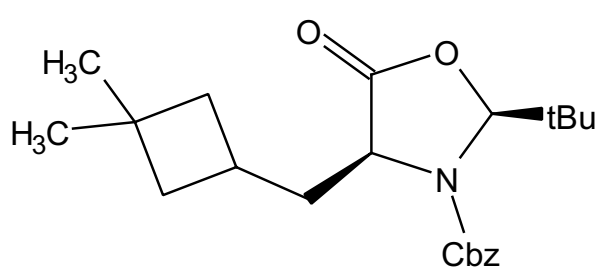

2h

$126 \mathrm{MHz}, \mathrm{CD}_{3} \mathrm{OD}$ 

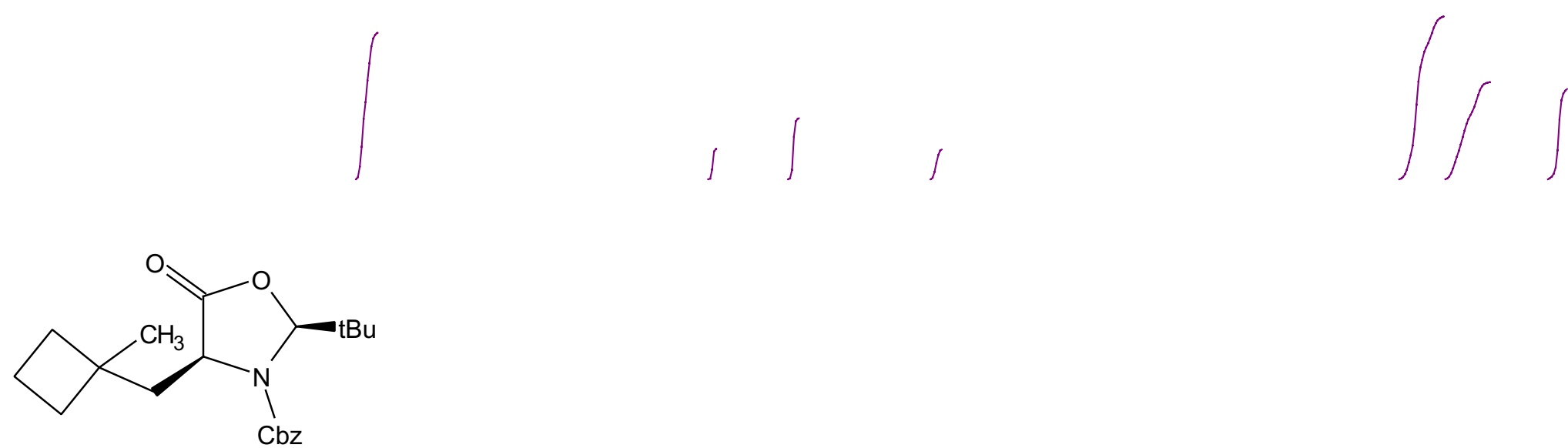

$2 \mathbf{i}$

$500 \mathrm{MHz}, \mathrm{CD}_{3} \mathrm{OD}$

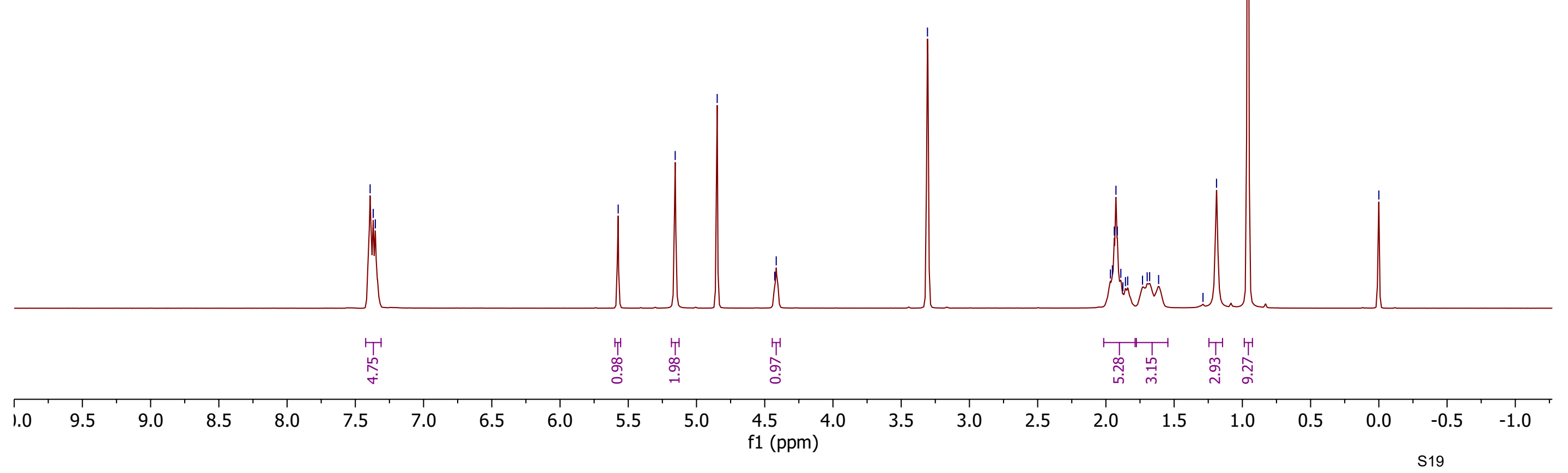




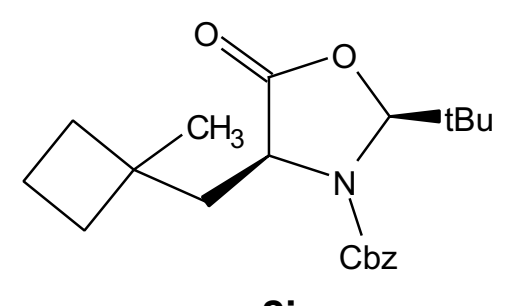

$2 \mathbf{i}$

$126 \mathrm{MHz}, \mathrm{CD}_{3} \mathrm{OD}$ 


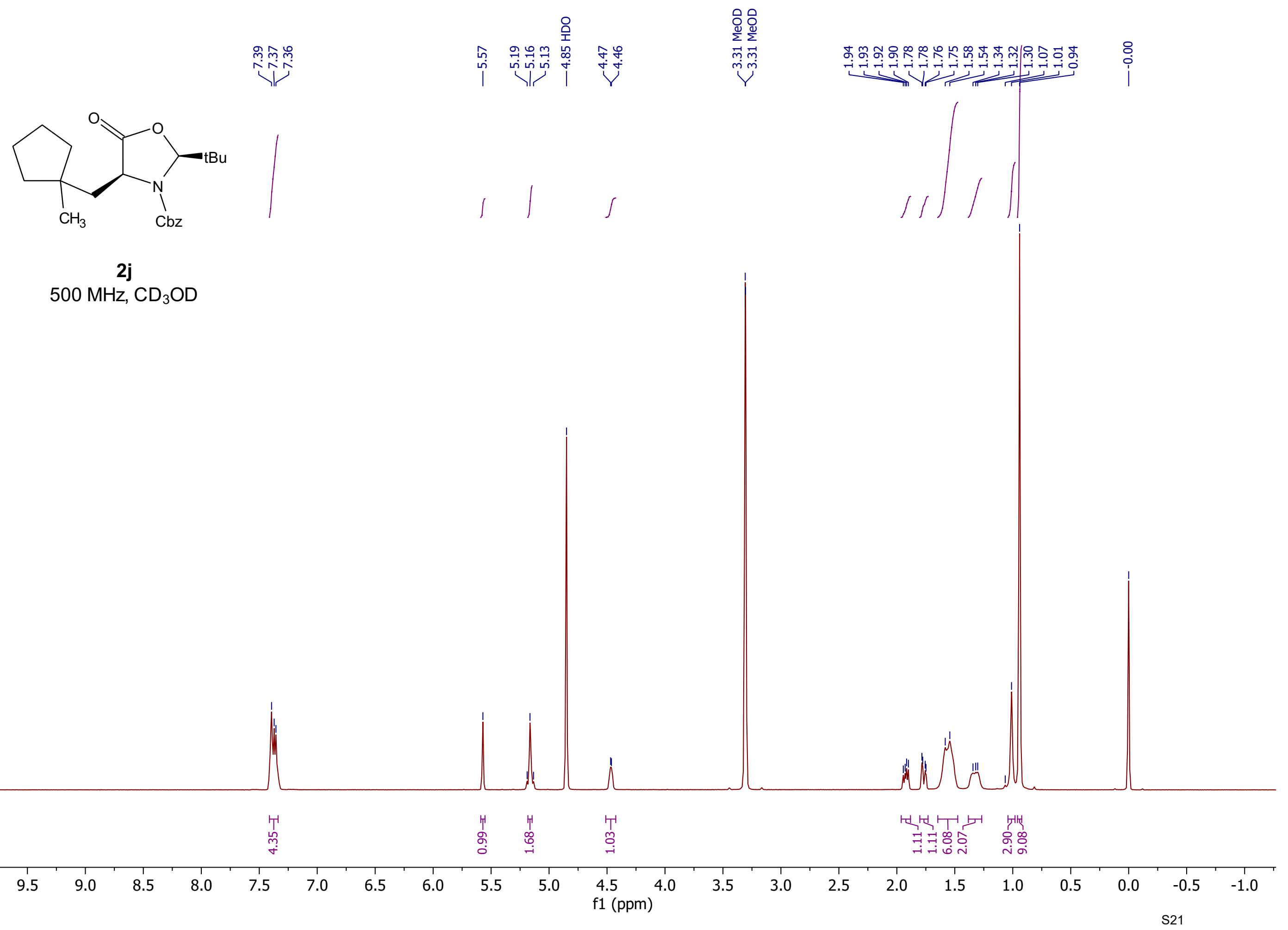




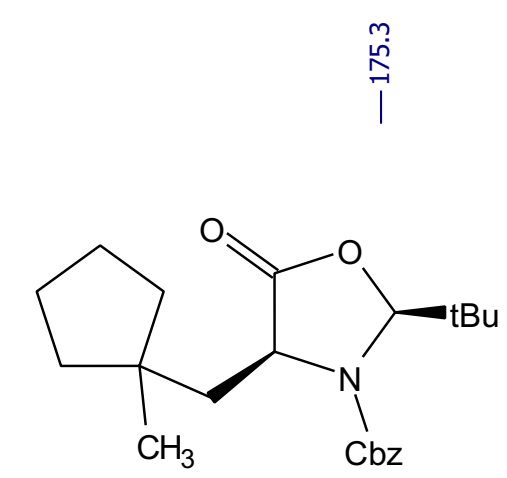

2j

$126 \mathrm{MHz}, \mathrm{CD}_{3} \mathrm{OD}$

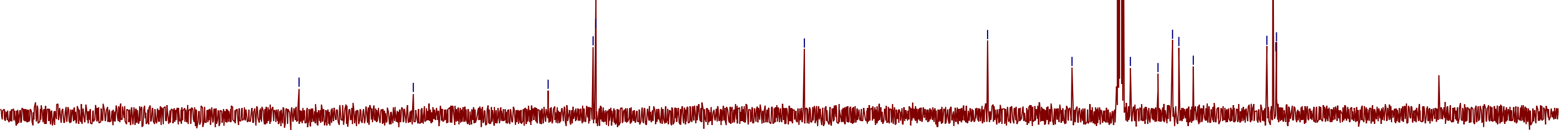

210200

190 $180 \quad 170$ 160 $50 \quad 140$ $30 \quad 120$ $110 \quad \begin{array}{ll}100 \\ \mathrm{f} 1(\mathrm{ppm})\end{array}$ 90 80

60

50

\begin{tabular}{rrrrrr}
\hline 40 & 30 & 20 & 10 & 0 & -10 \\
& & & \\
& & &
\end{tabular}




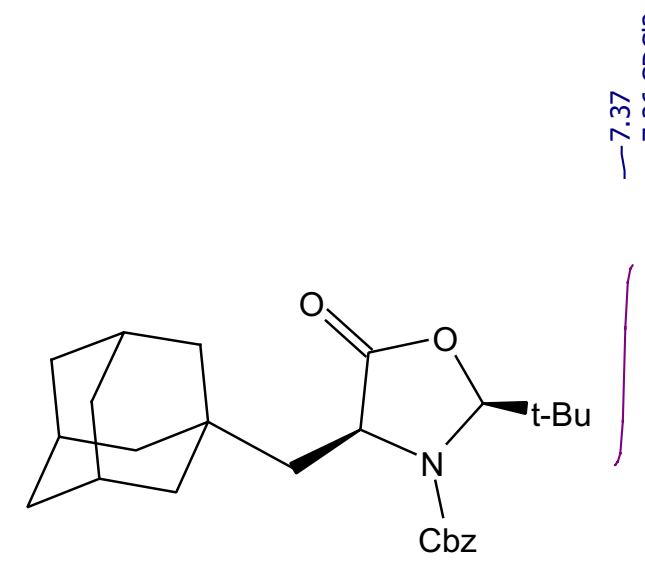

2k

$500 \mathrm{MHz}, \mathrm{CDCl}_{3}$

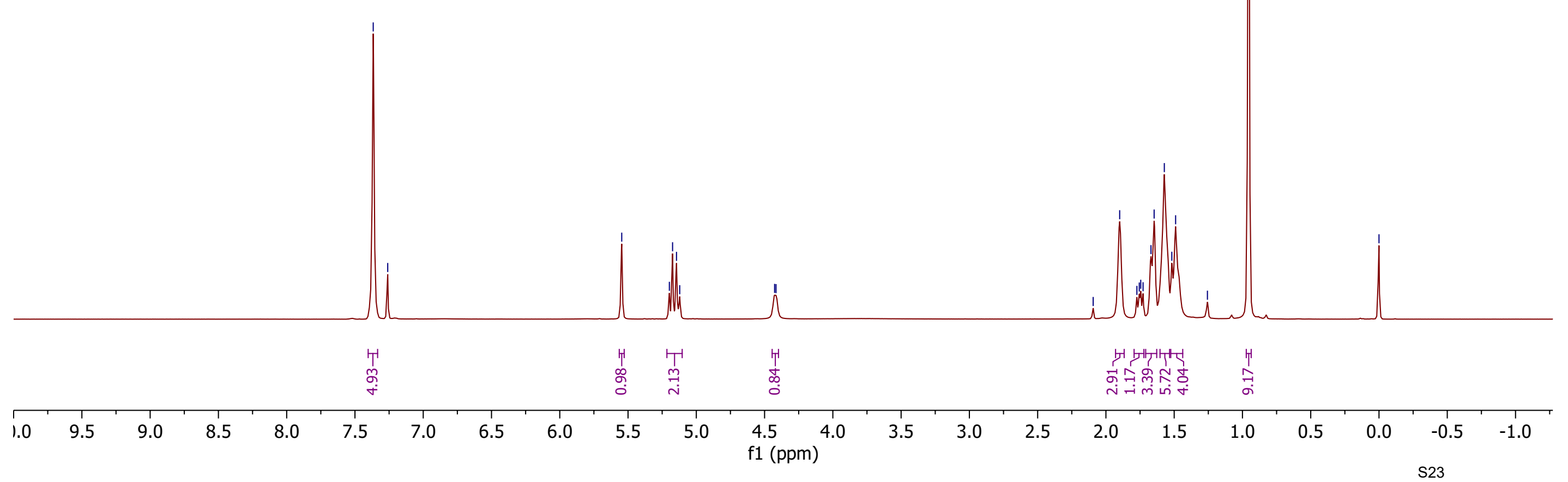




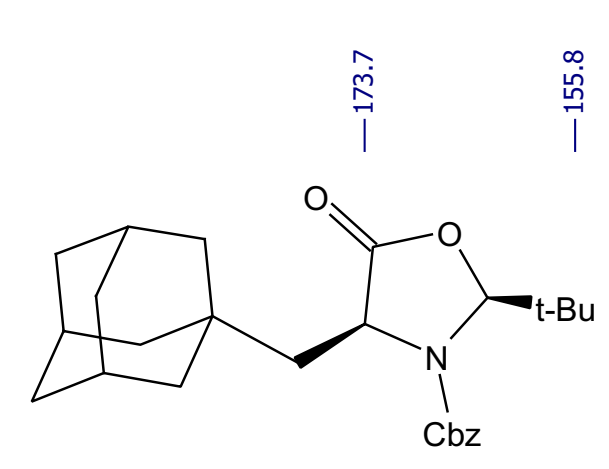

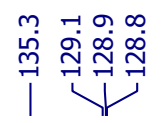

$2 k$

$126 \mathrm{MHz} \mathrm{CDCl}_{3}$

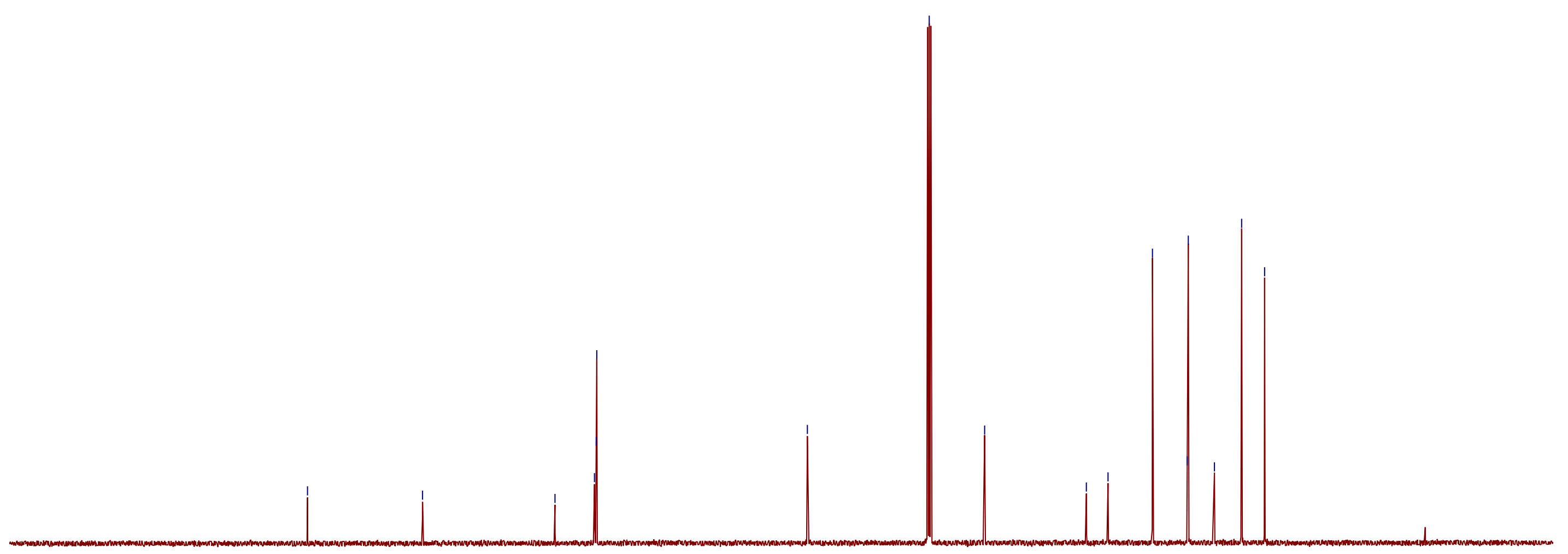




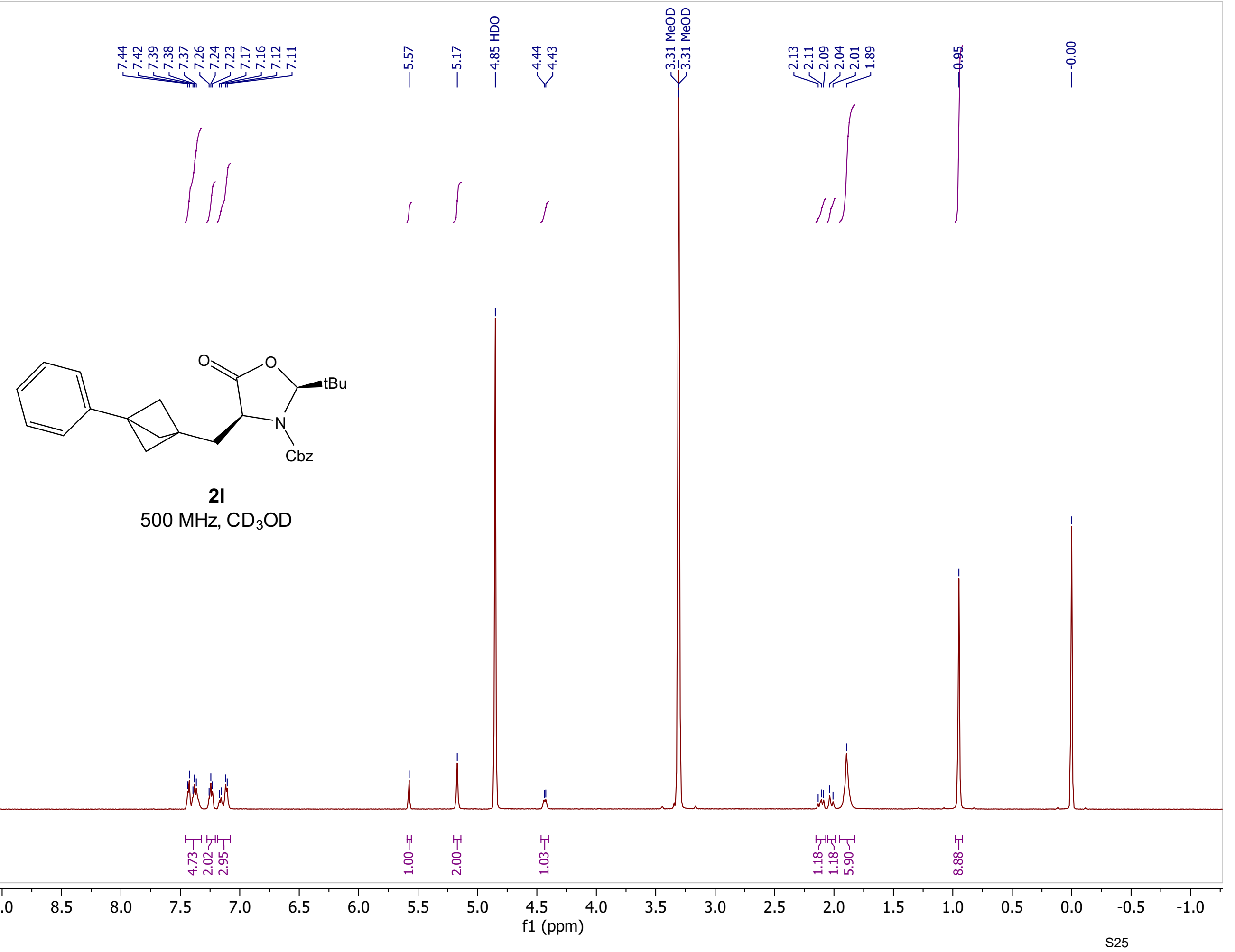



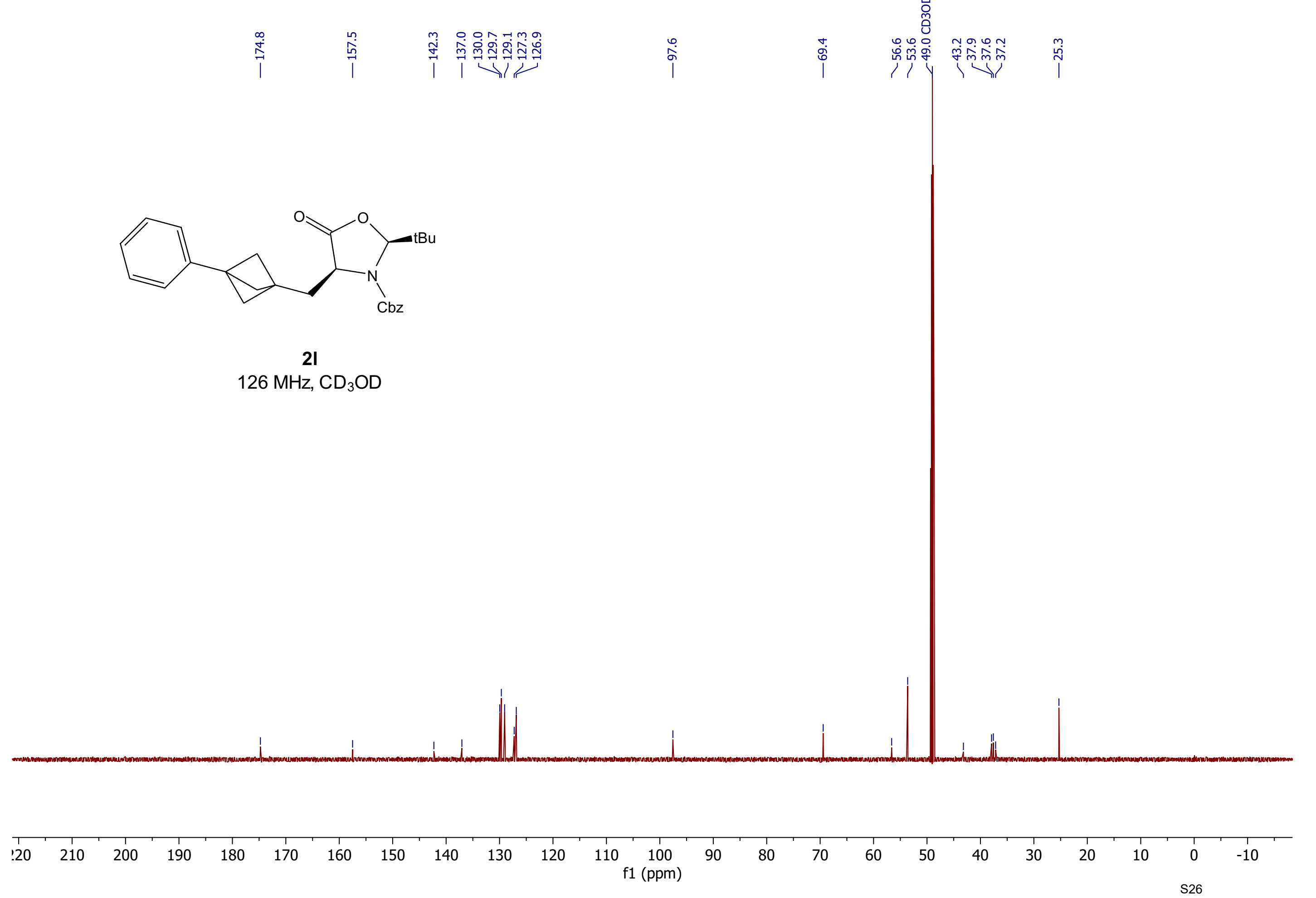
<smiles>CC(C)(C)CC[C@H]1C(=O)OC(C)(C)N1CCCCCC(=O)c1ccccc1</smiles>

$2 \mathrm{~m}$

$500 \mathrm{MHz}, \mathrm{CD}_{3} \mathrm{OD}$

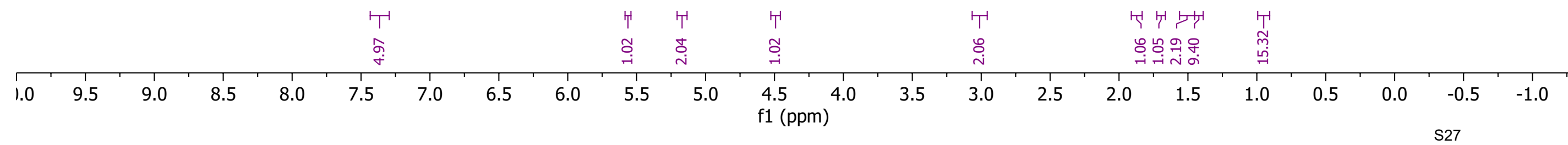




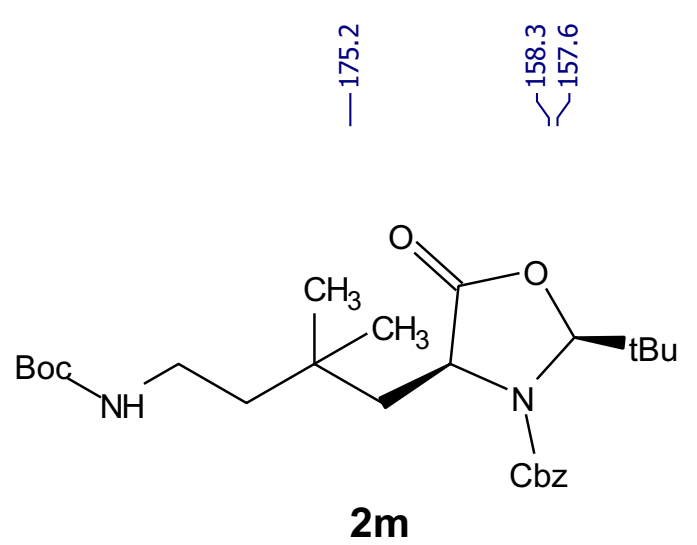

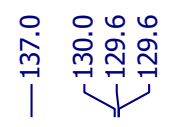

$126 \mathrm{MHz}, \mathrm{CD}_{3} \mathrm{OD}$
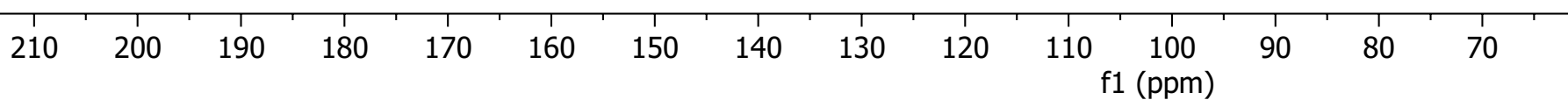

60

$50 \quad 40$

$\begin{array}{rrrrrr}40 & 30 & 20 & 10 & 0 & -10 \\ & & & & \end{array}$ 


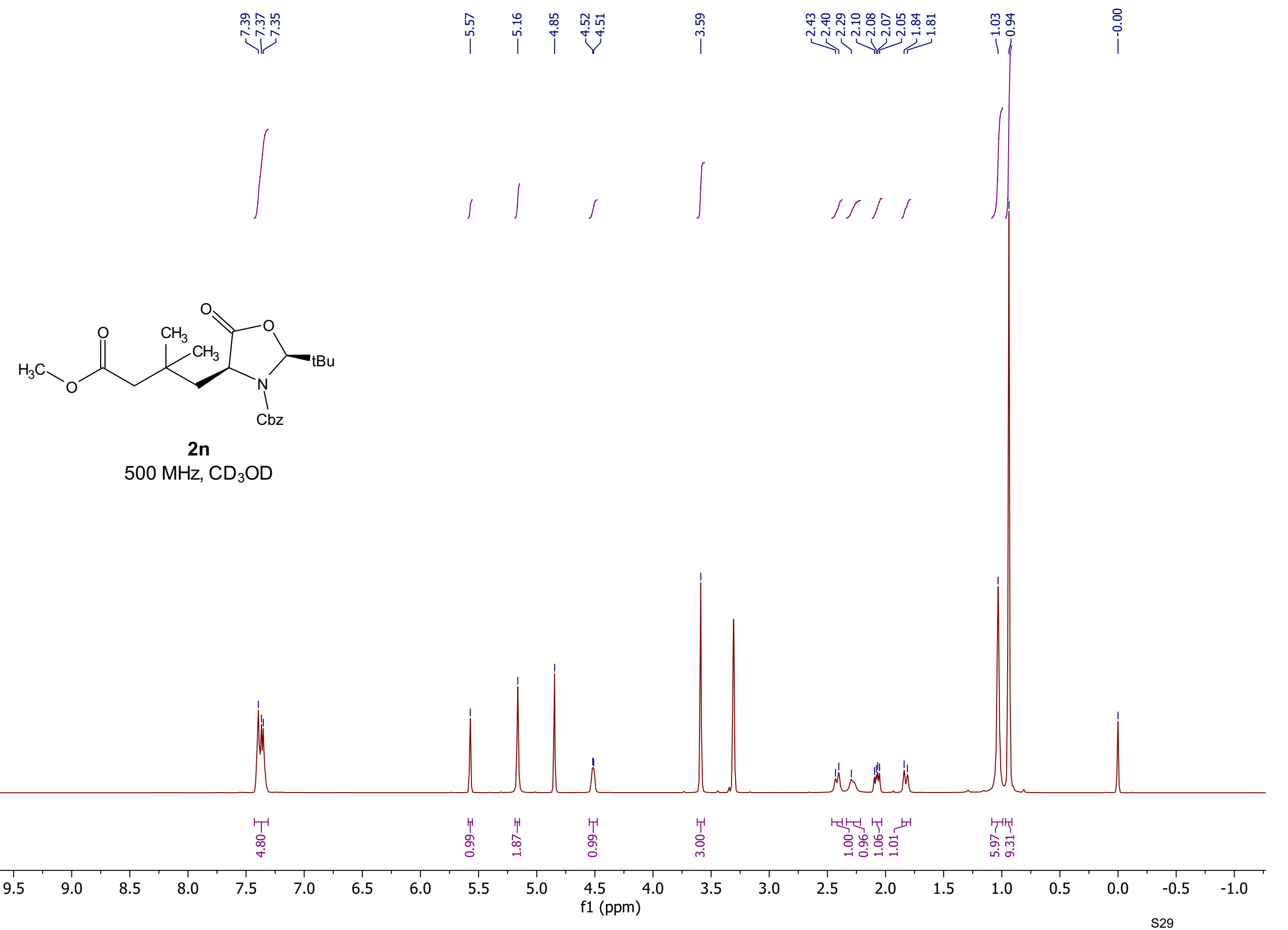



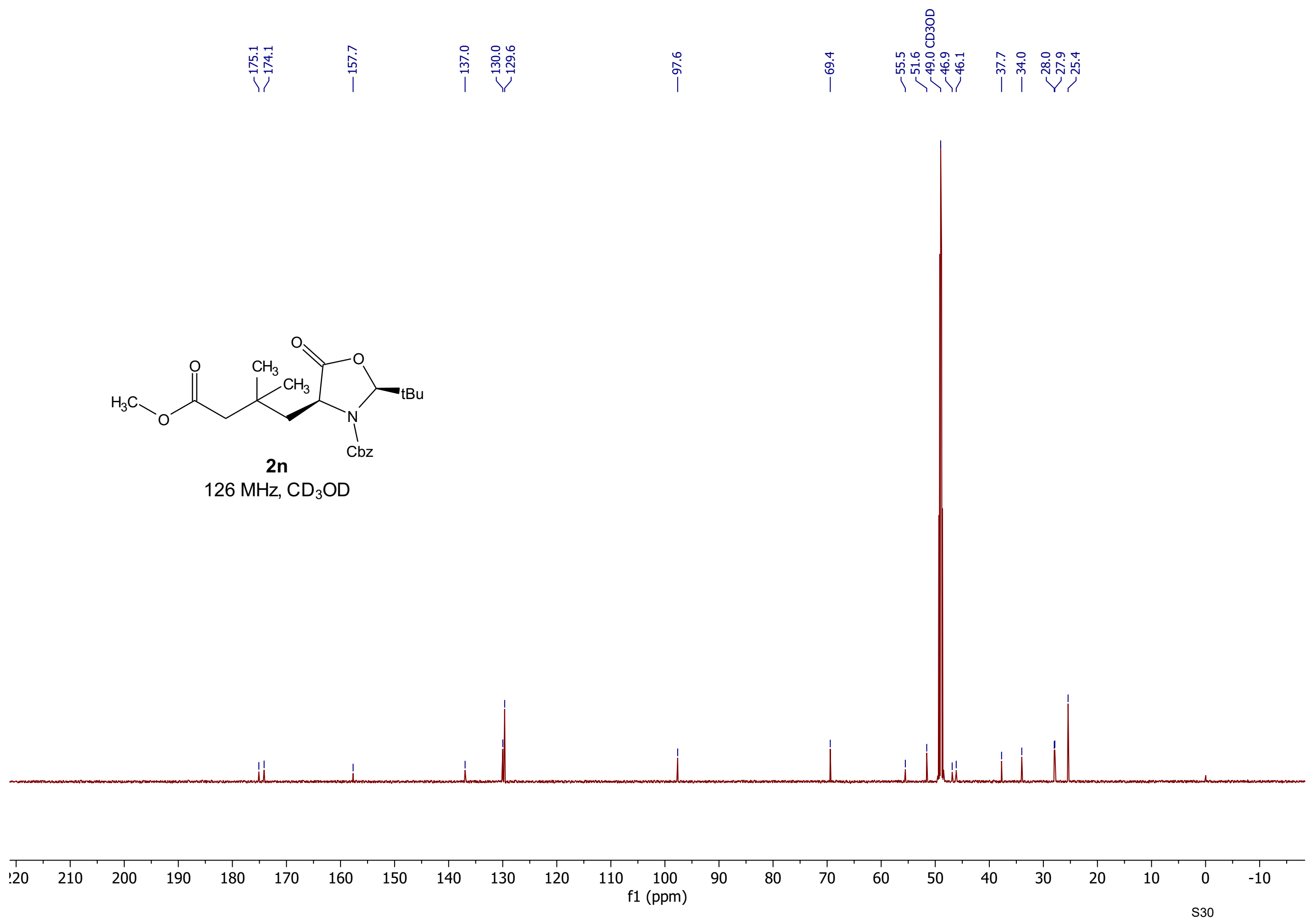


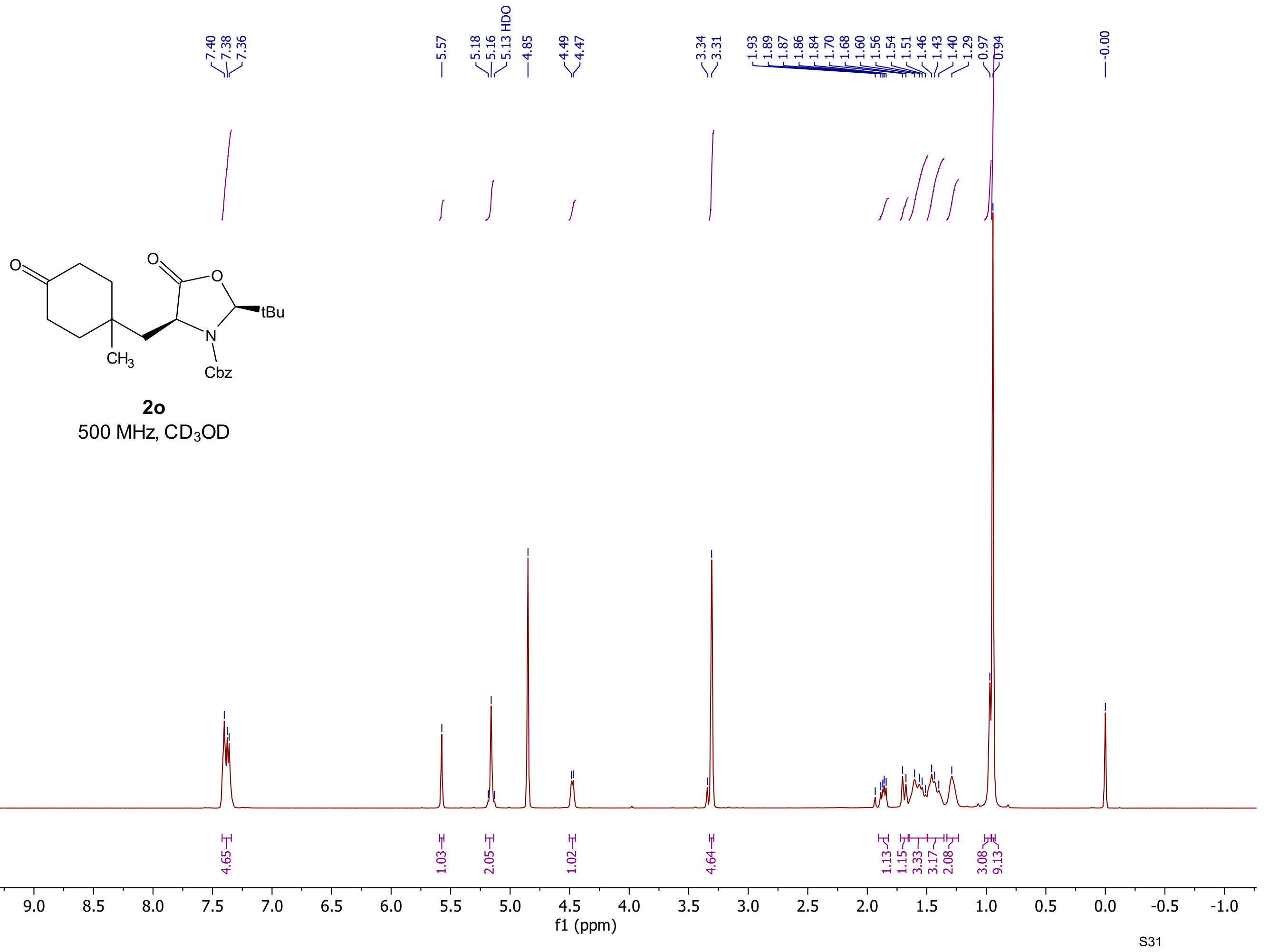




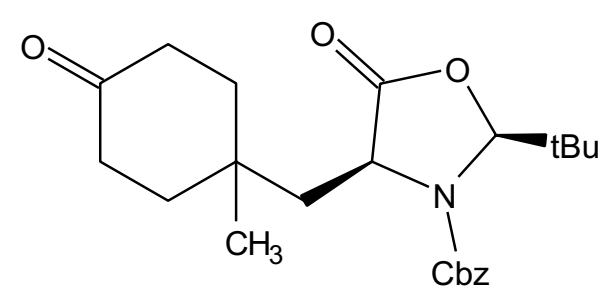

20

$126 \mathrm{MHz}, \mathrm{CD}_{3} \mathrm{OD}$ 


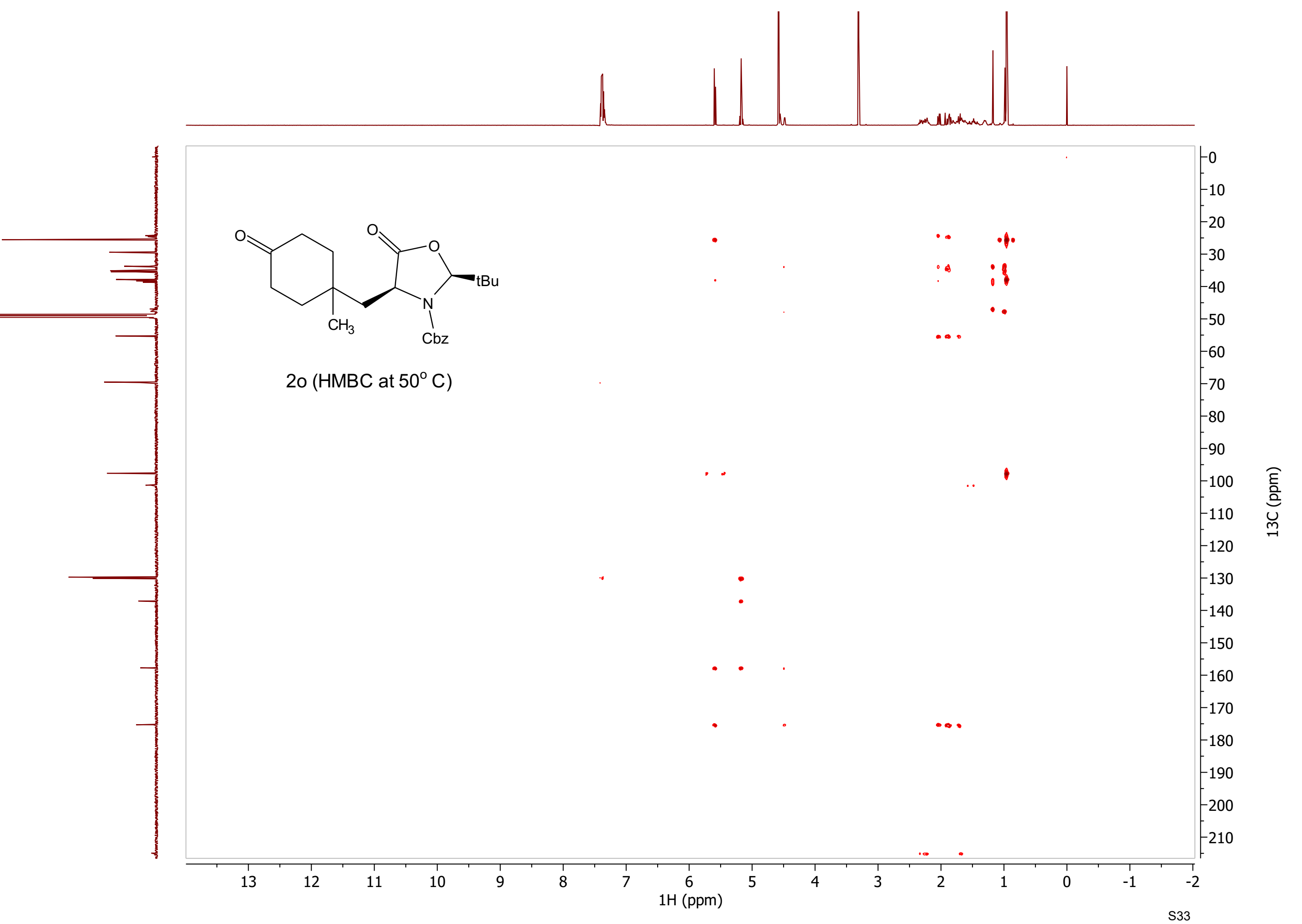


$\int$
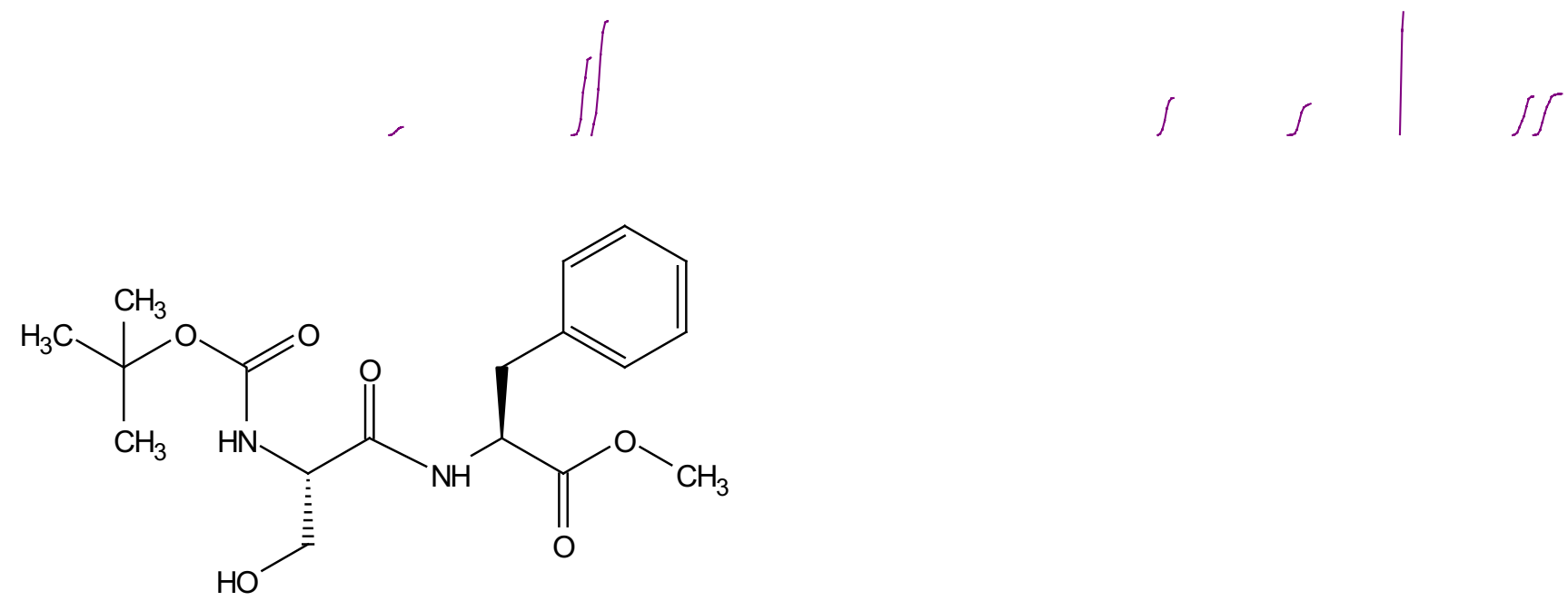

$3 a$

$500 \mathrm{MHz}, \mathrm{CD}_{3} \mathrm{OD}$
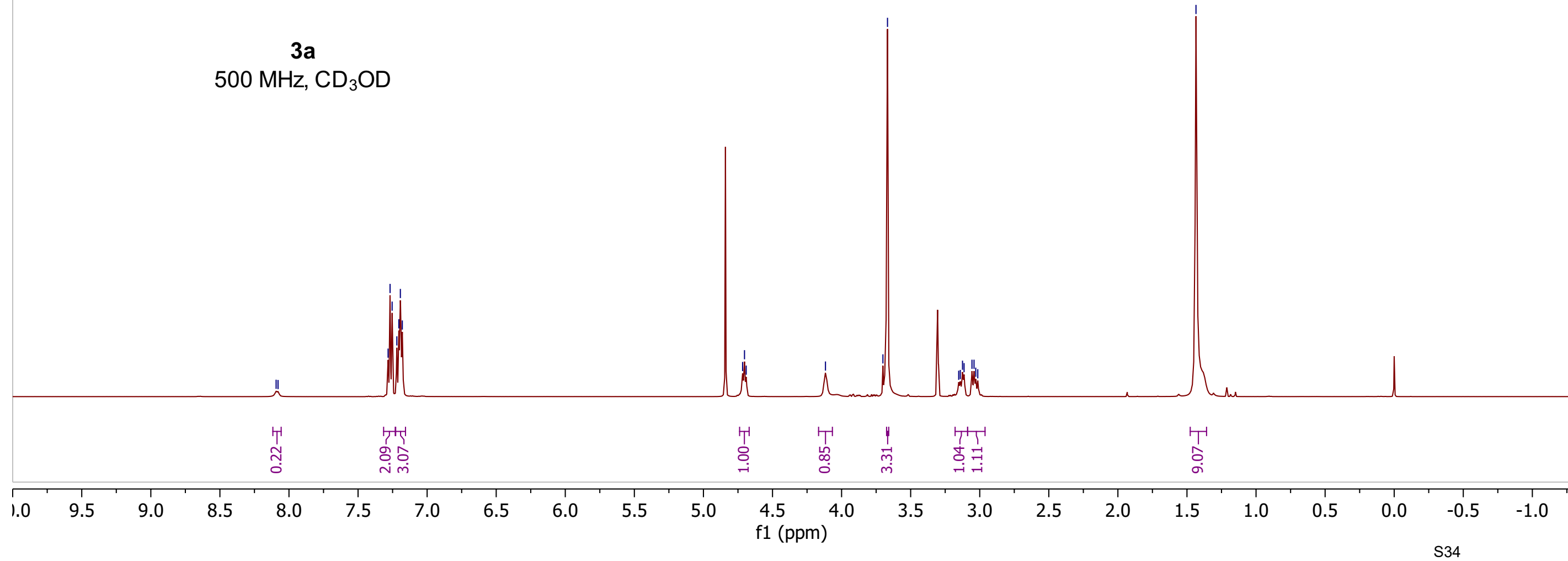

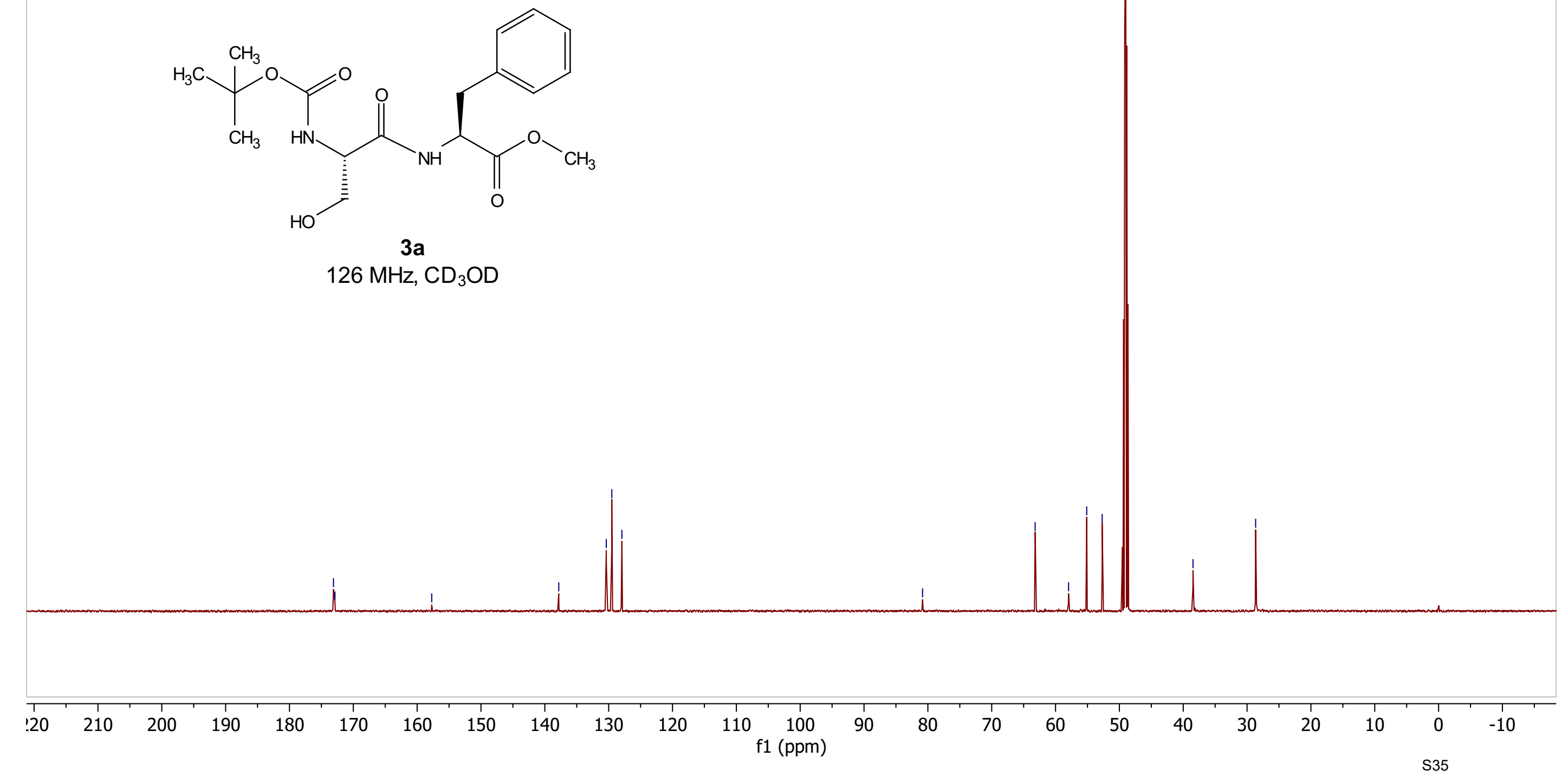


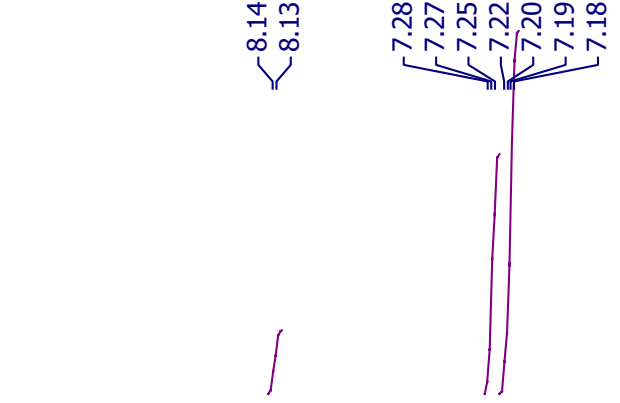<smiles>COC(=O)[C@H](Cc1ccccc1)NC(=O)[C@H](CO)NC(=O)[C@H](CC(C)C)NC(C)=O</smiles>

$3 b$

$500 \mathrm{MHz}, \mathrm{CD}_{3} \mathrm{OD}$

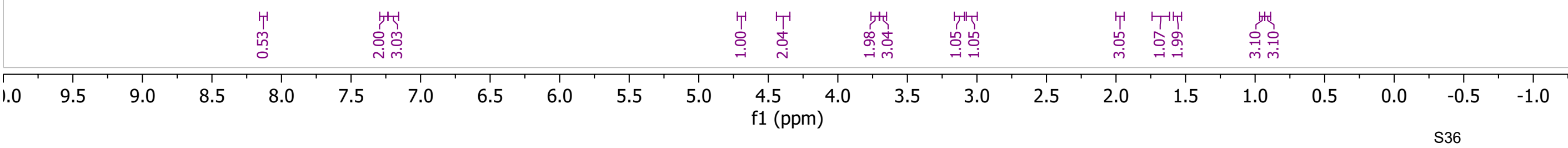



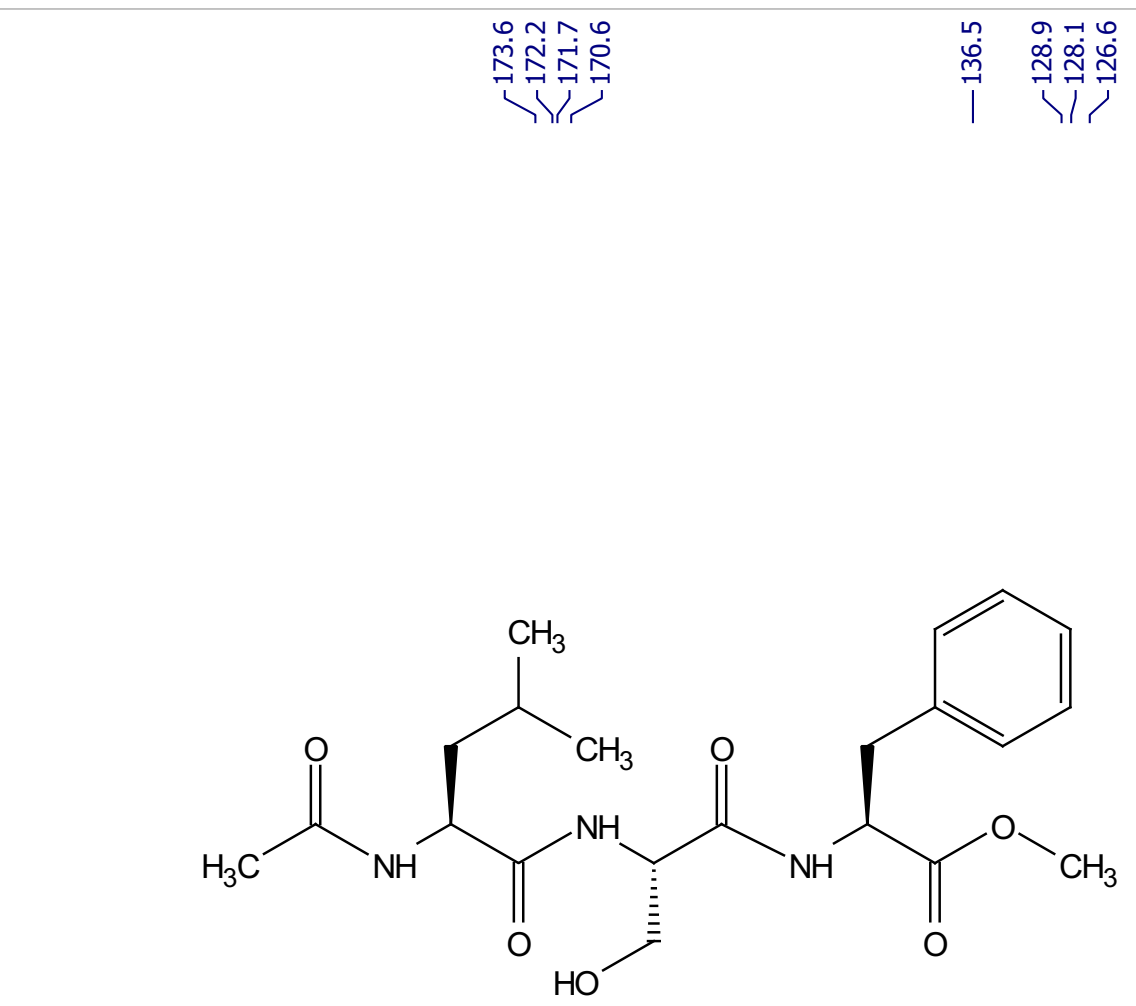

3b

$126 \mathrm{MHz}, \mathrm{CD}_{3} \mathrm{OD}$

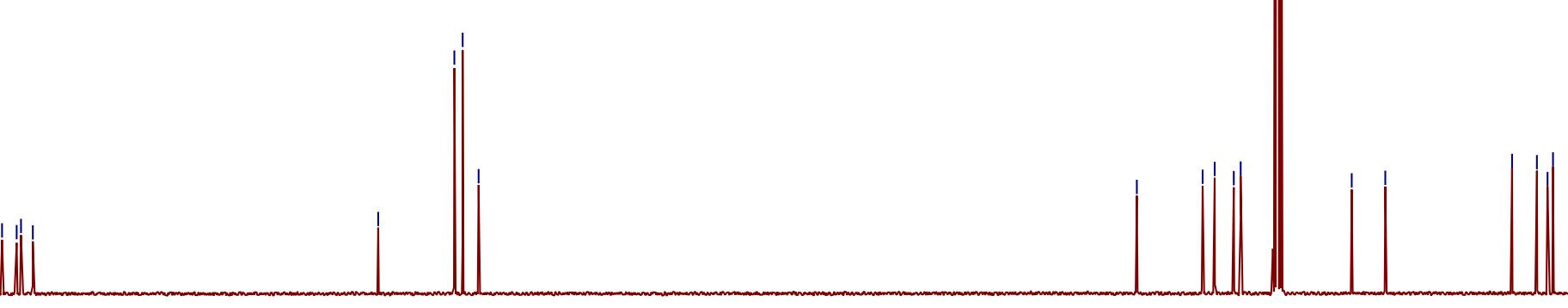




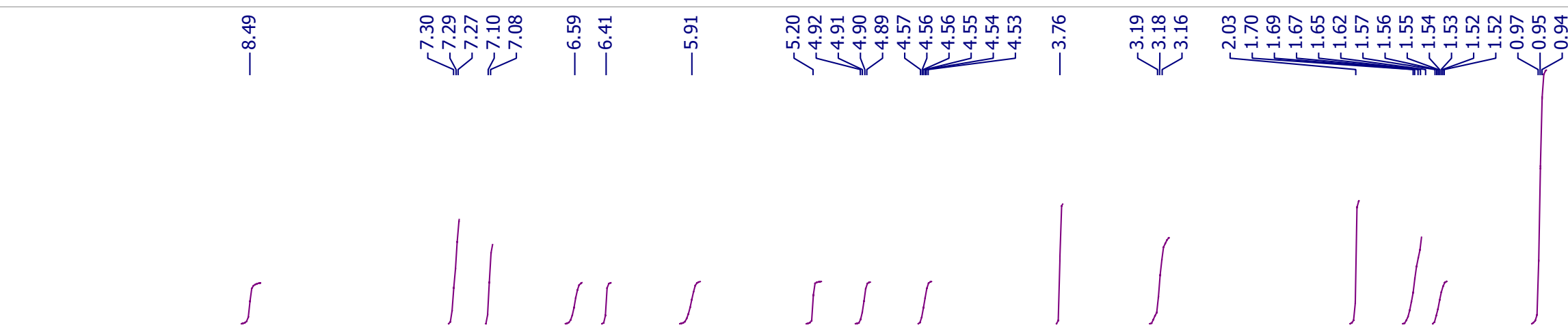<smiles>C=C(NC(=O)[C@H](CC(C)C)NC(C)=O)C(=O)N[C@@H](Cc1ccccc1)C(=O)OC</smiles>

3

$500 \mathrm{MHz}, \mathrm{CDCl}_{3}$

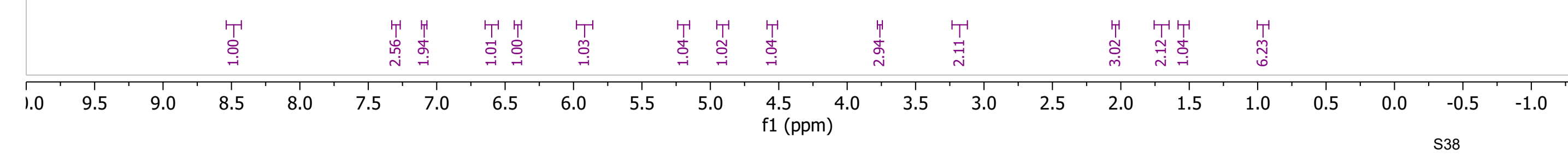



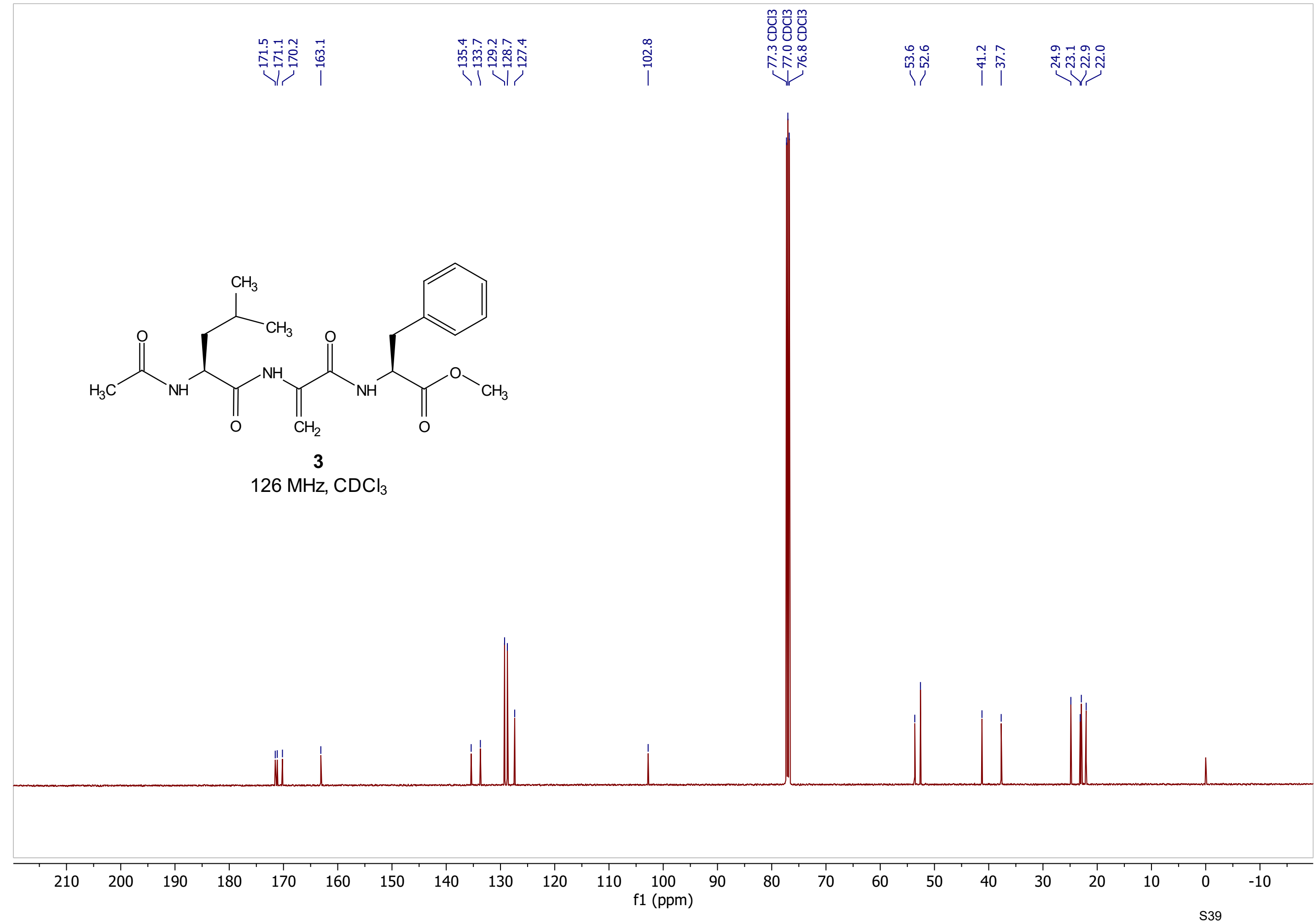


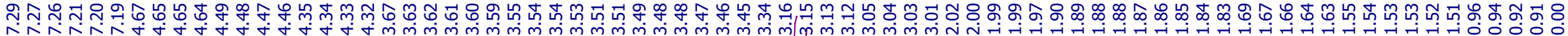
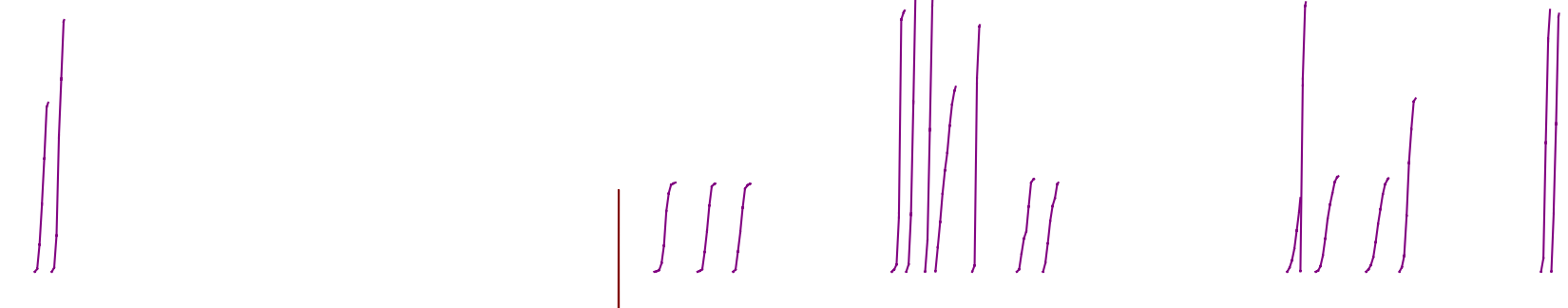<smiles>COCCOCCOCCC(NC(=O)[C@H](CC(C)C)NC(C)=O)C(=O)N[C@@H](Cc1ccccc1)C(=O)OC</smiles>

4a - isomer 1 $500 \mathrm{MHz}, \mathrm{CD}_{3} \mathrm{OD}$<smiles>C#CC#C</smiles>
int Wit
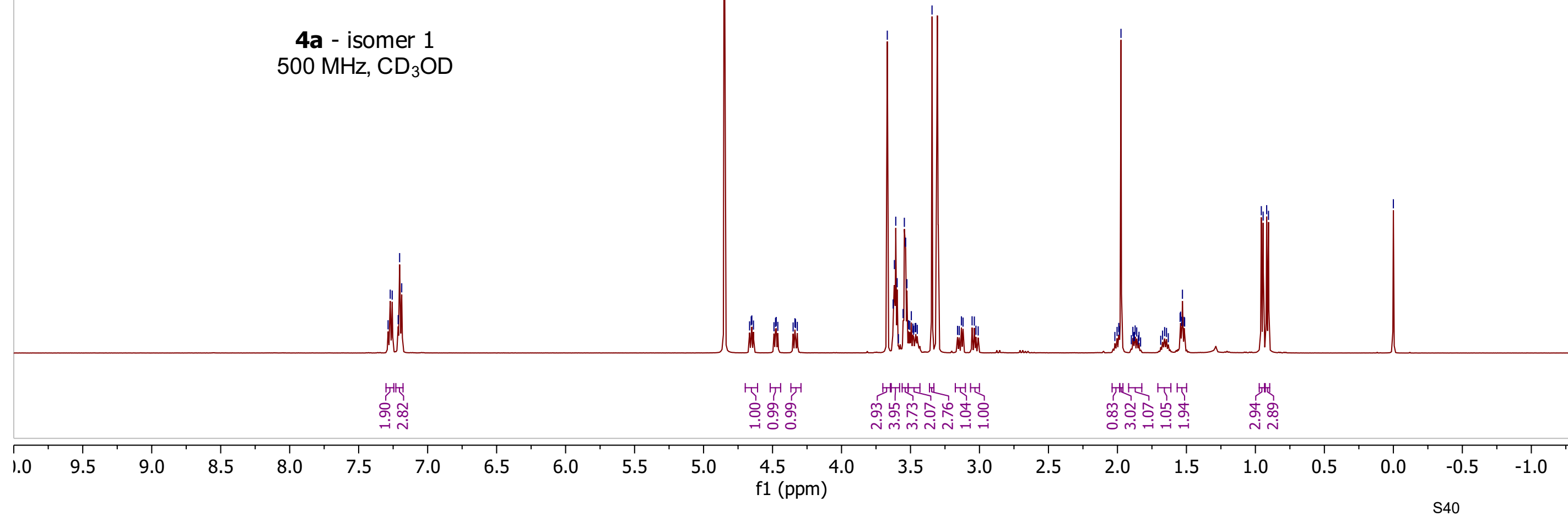


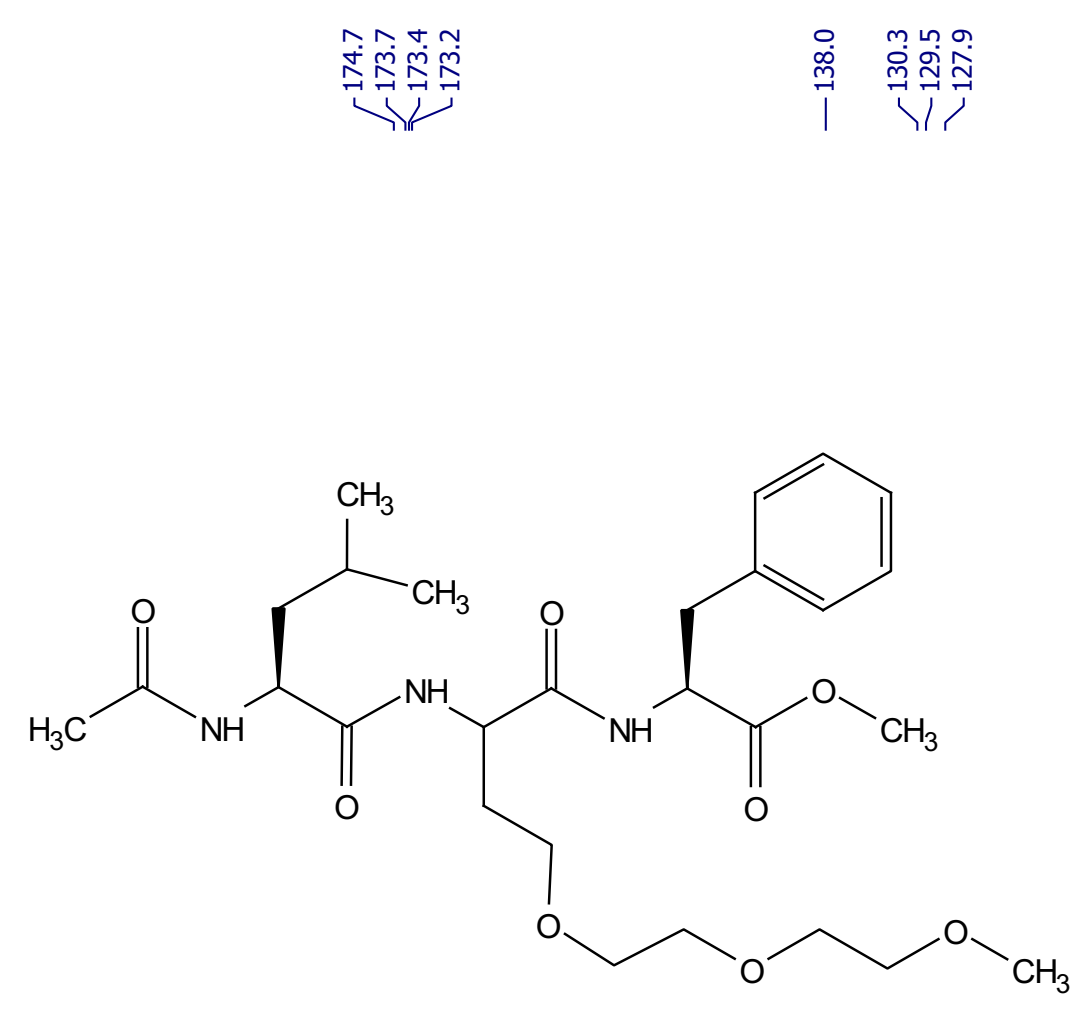

$4 a$ - isomer 1

$126 \mathrm{MHz}, \mathrm{CD}_{3} \mathrm{OD}$

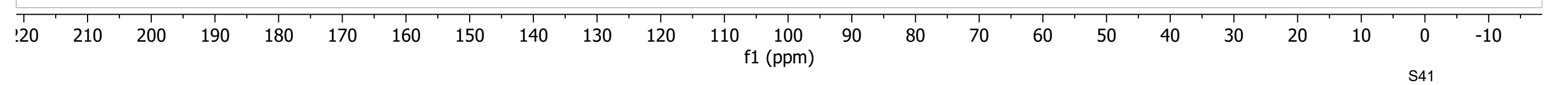




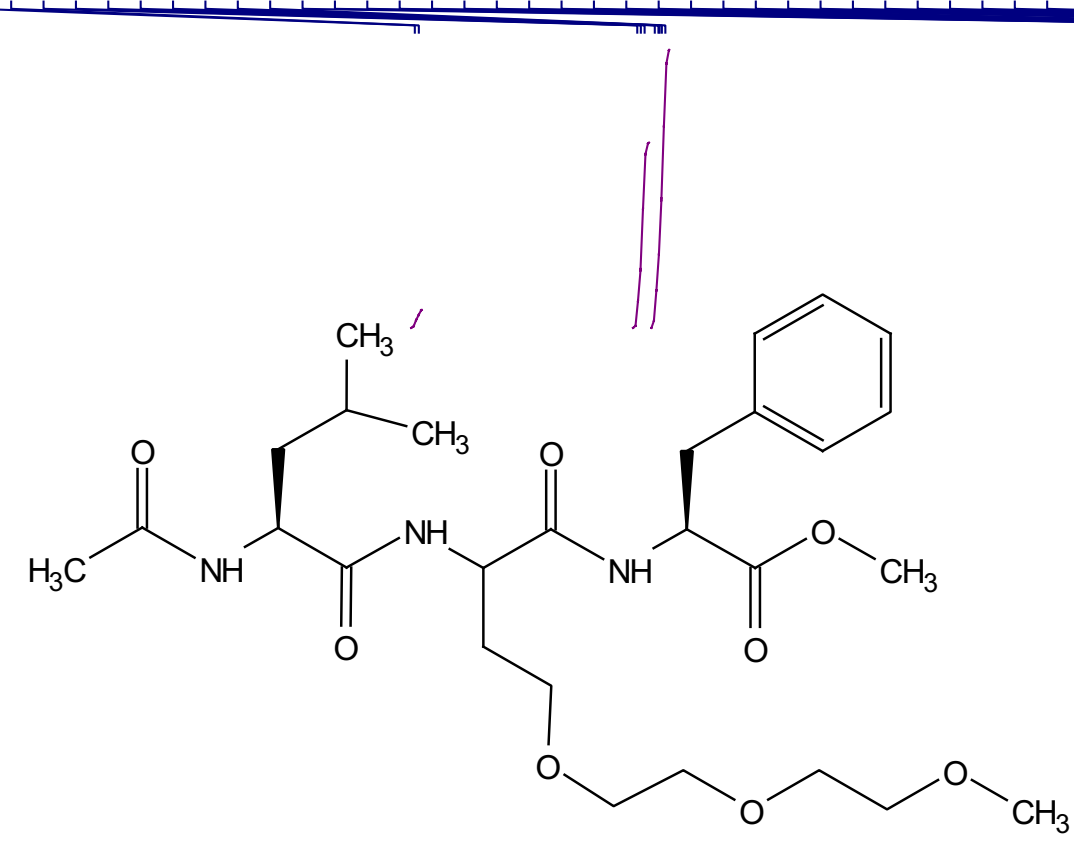

$4 a$ - isomer 2

$500 \mathrm{MHz}, \mathrm{CD}_{3} \mathrm{OD}$
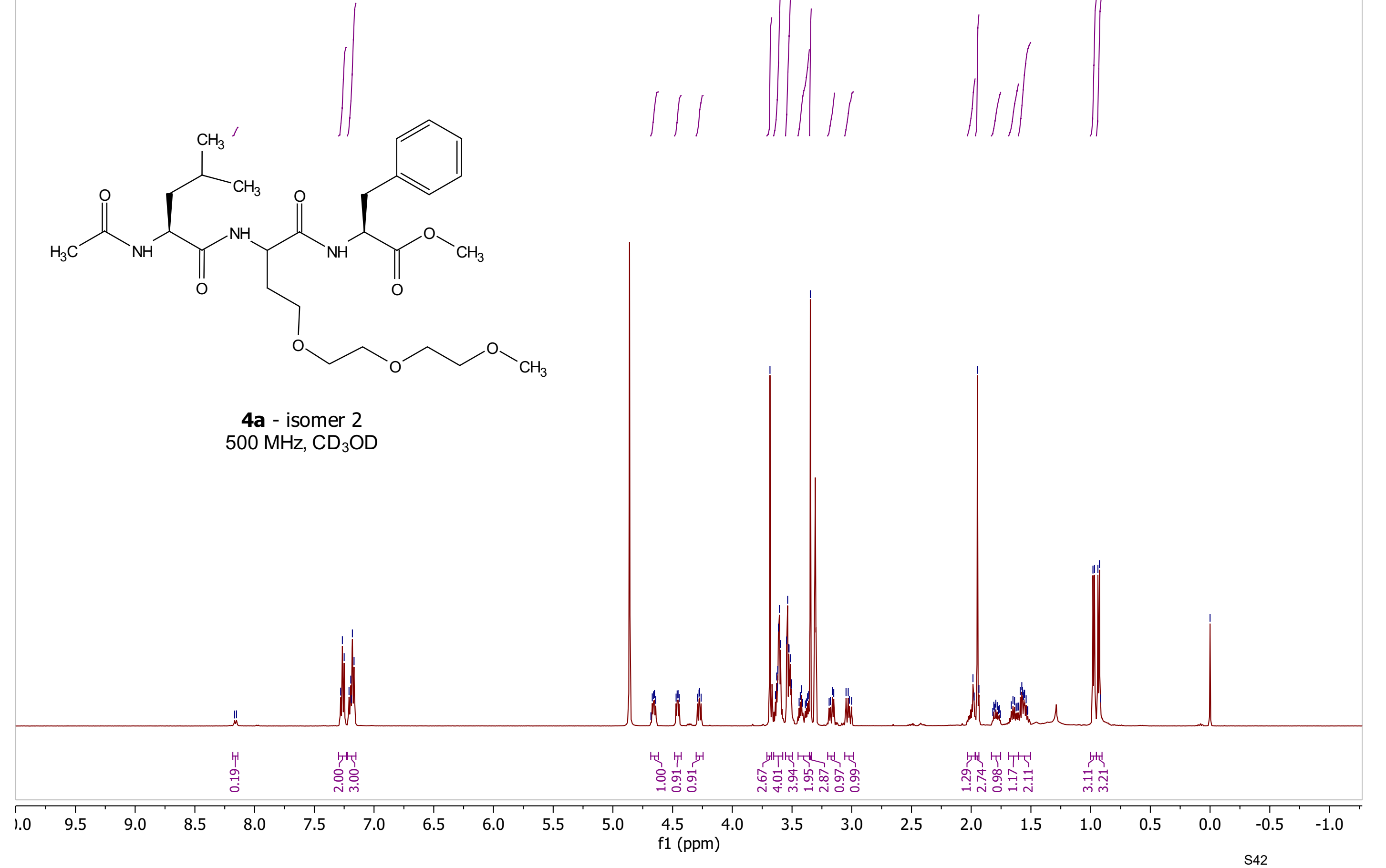


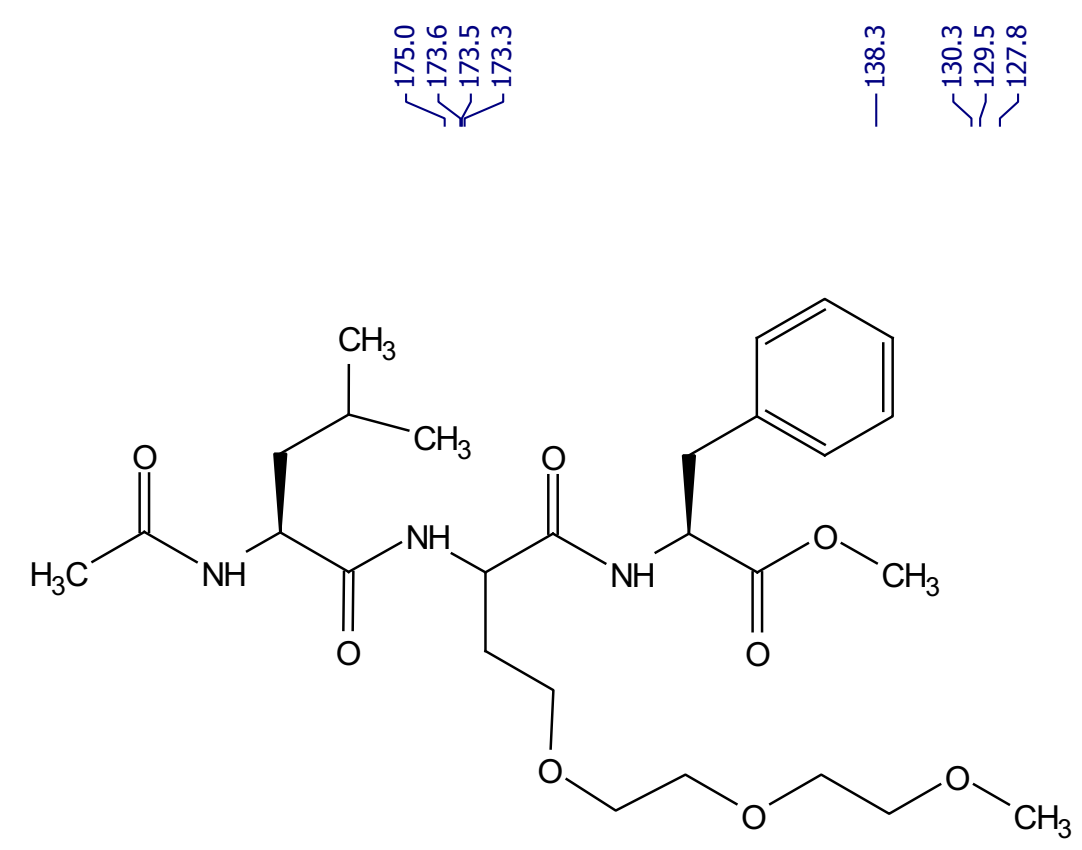

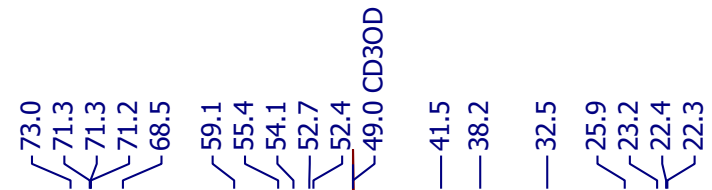

4a - isomer 2 $126 \mathrm{MHz}, \mathrm{CD}_{3} \mathrm{OD}$ 
<smiles>COC(=O)[C@H](Cc1ccccc1)NC(=O)C(CC1CCOCC1)NC(=O)[C@H](CC(C)C)NC(C)=O</smiles>

4b -isomer 1 $500 \mathrm{MHz}, \mathrm{CD}_{3} \mathrm{OD}$

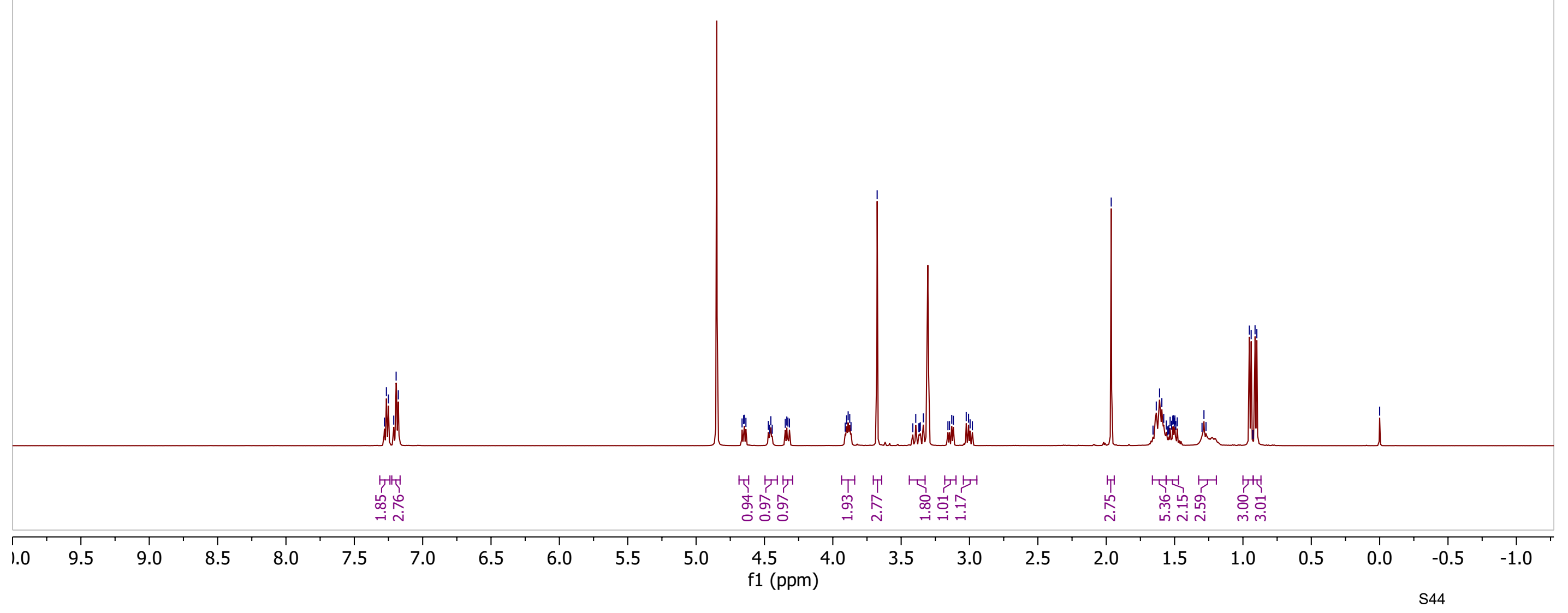



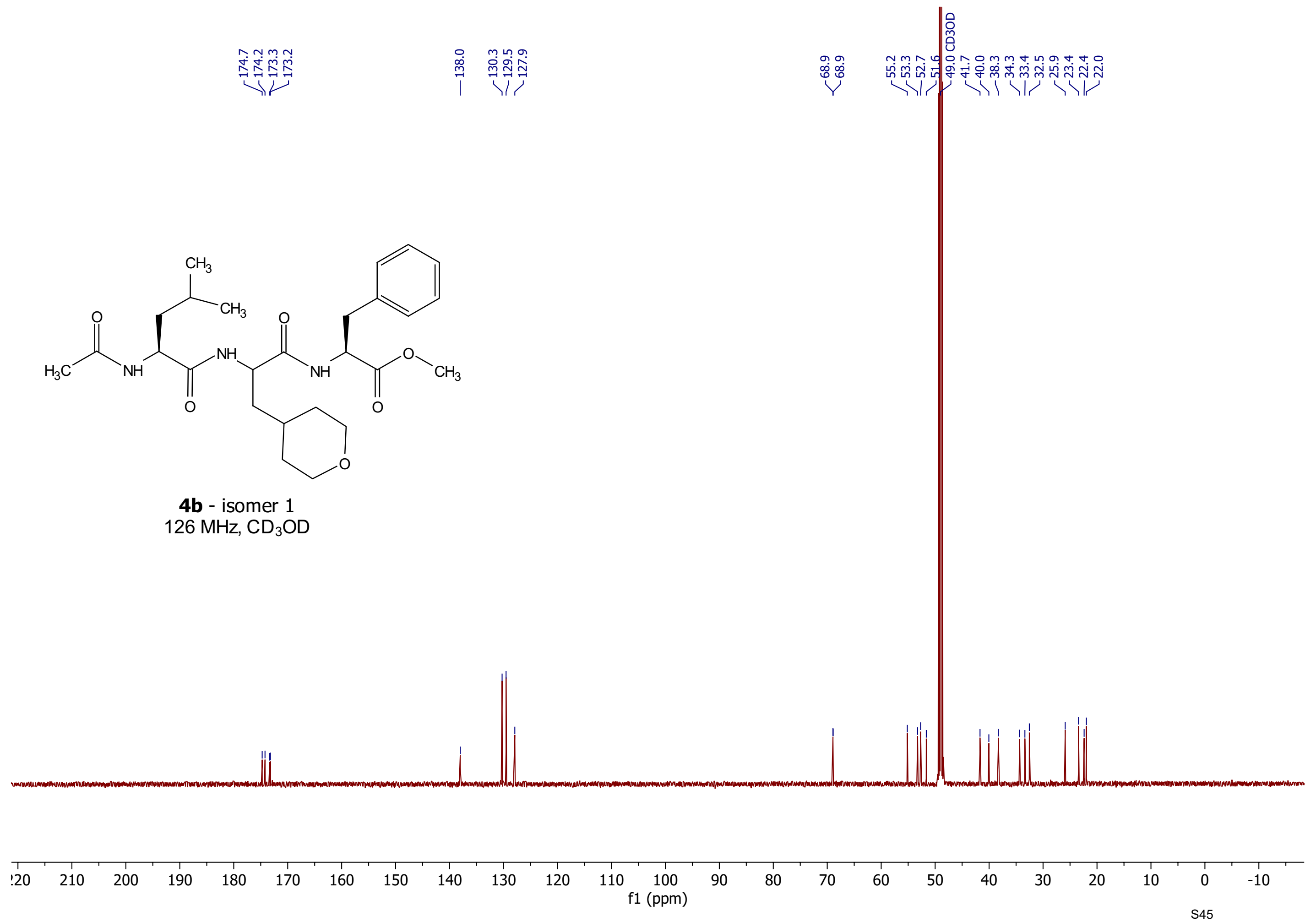
<smiles>COC(=O)[C@H](Cc1ccccc1)NC(=O)C(CC1CCOCC1)NC(=O)[C@H](CC(C)C)NC(C)=O</smiles>

4b - isomer 2

$500 \mathrm{MHz}, \mathrm{CD}_{3} \mathrm{OD}$

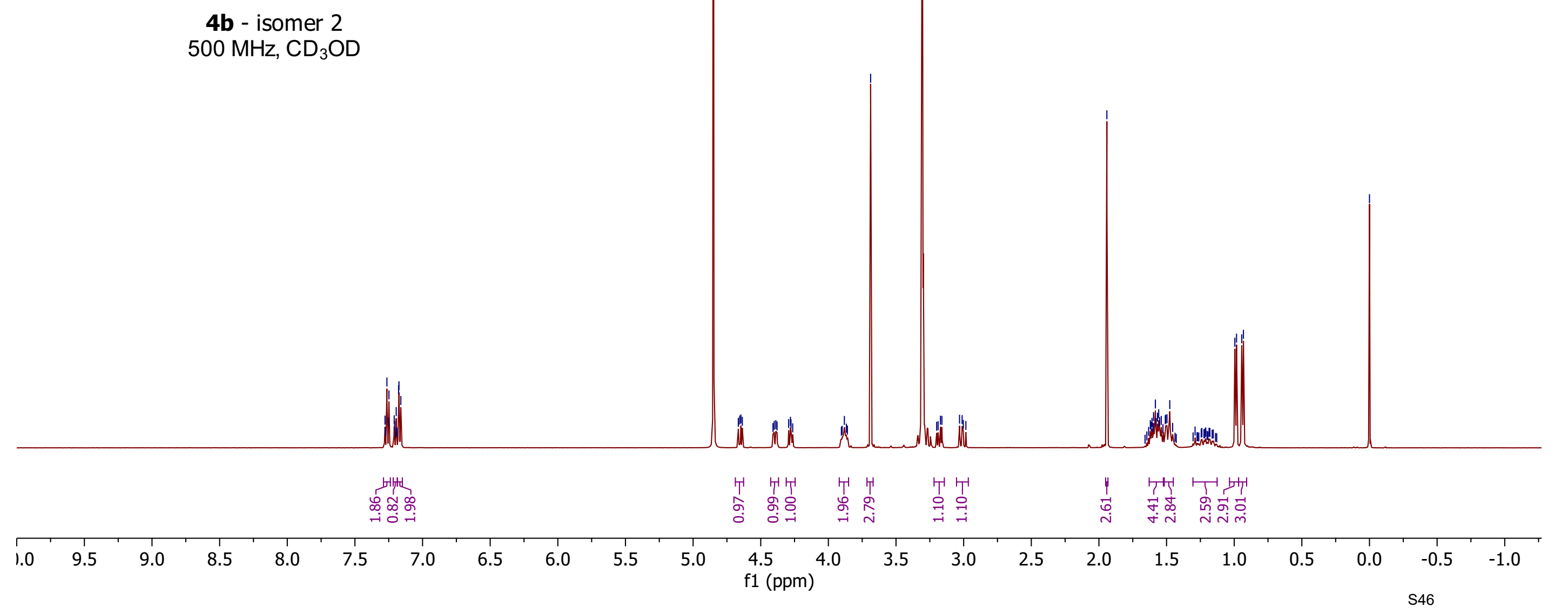




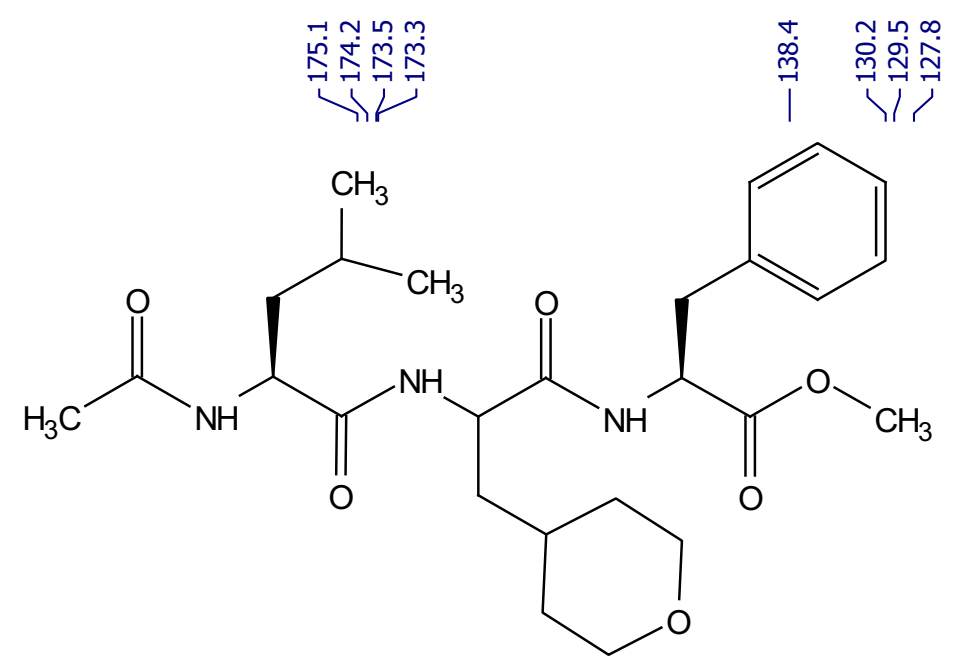

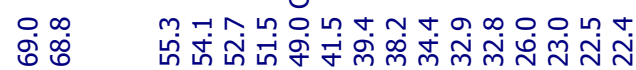

4b - isomer 2

$126 \mathrm{MHz}, \mathrm{CD}_{3} \mathrm{OD}$

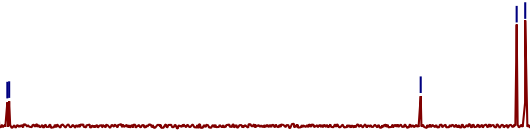

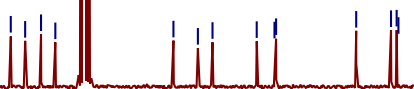




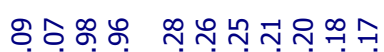

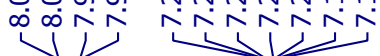

(1)

II $\quad 1$

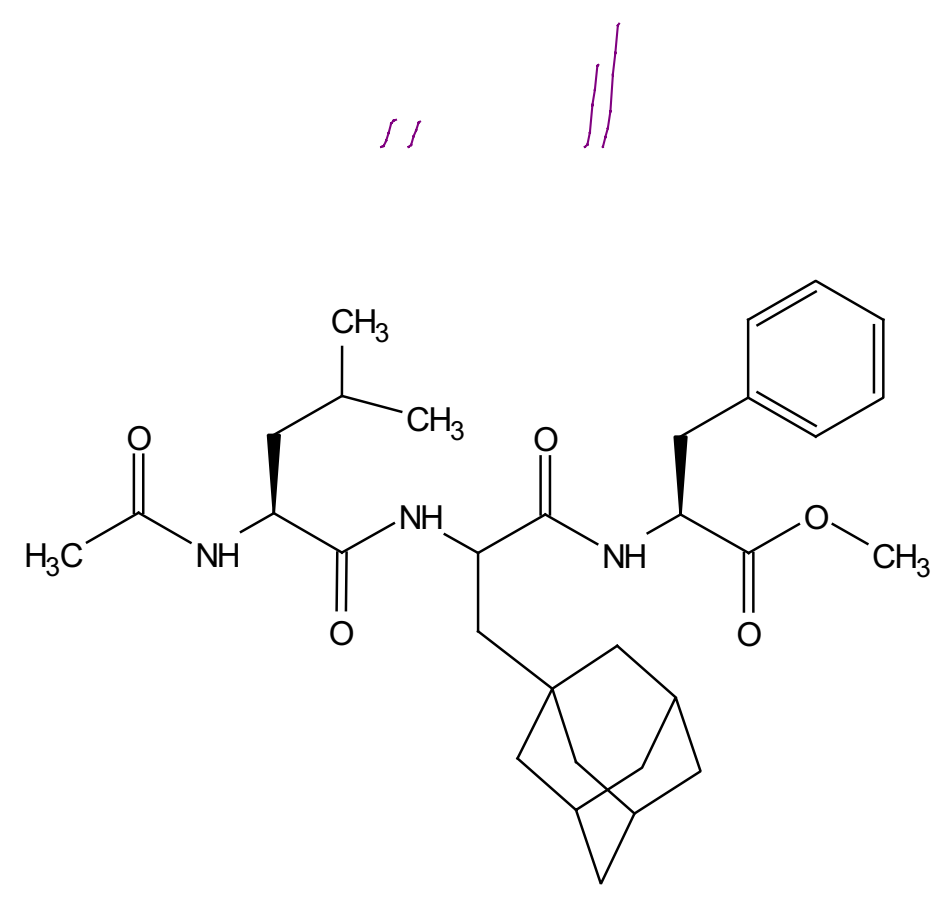

4c - isomer 1

$500 \mathrm{MHz}, \mathrm{CD}_{3} \mathrm{OD}$
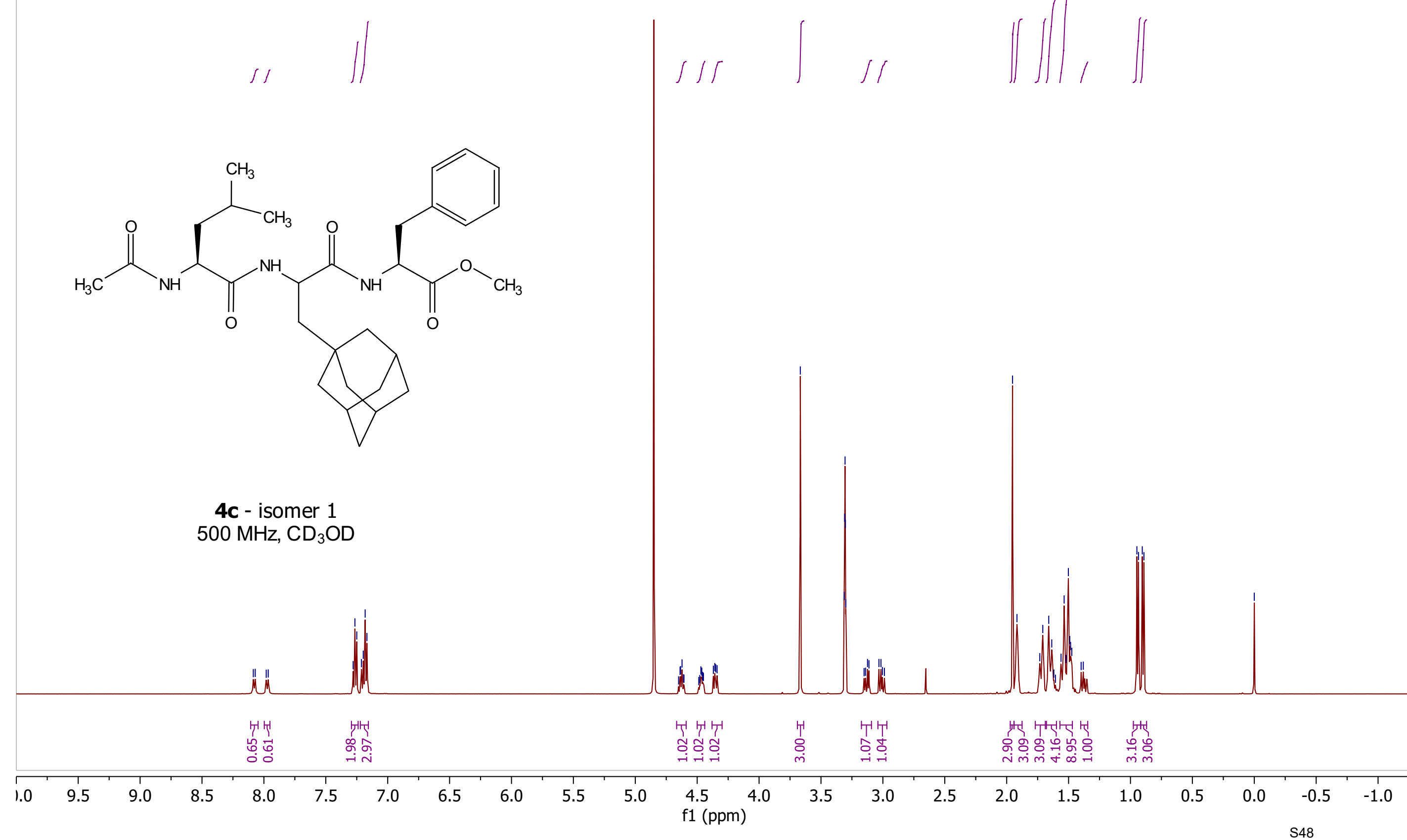


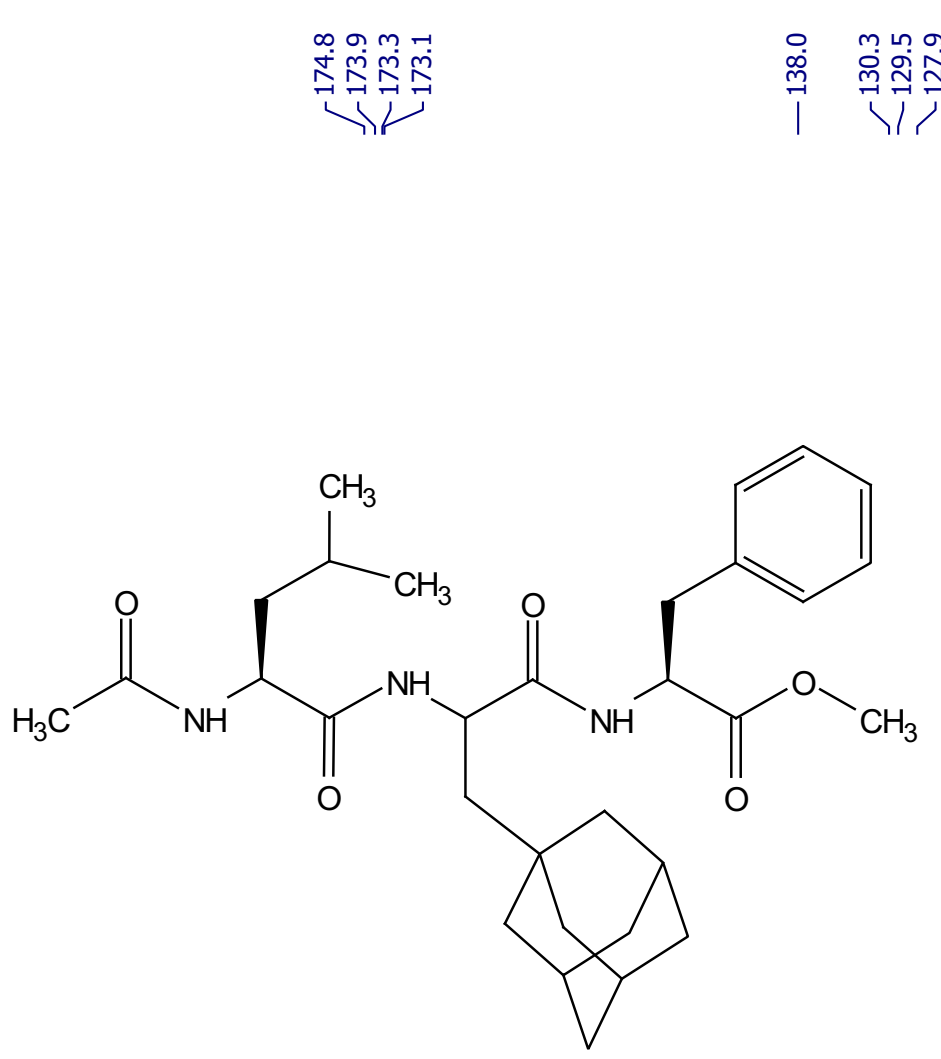

4c - isomer 1

$126 \mathrm{MHz}, \mathrm{CD}_{3} \mathrm{OD}$

in 


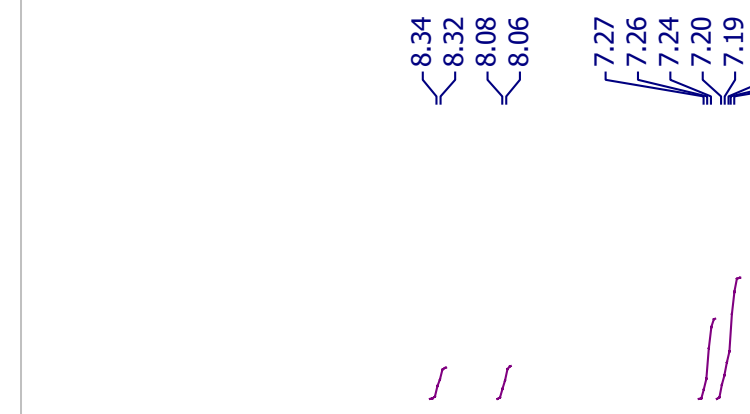

4c - isomer 2

$500 \mathrm{MHz}, \mathrm{CD}_{3} \mathrm{OD}$

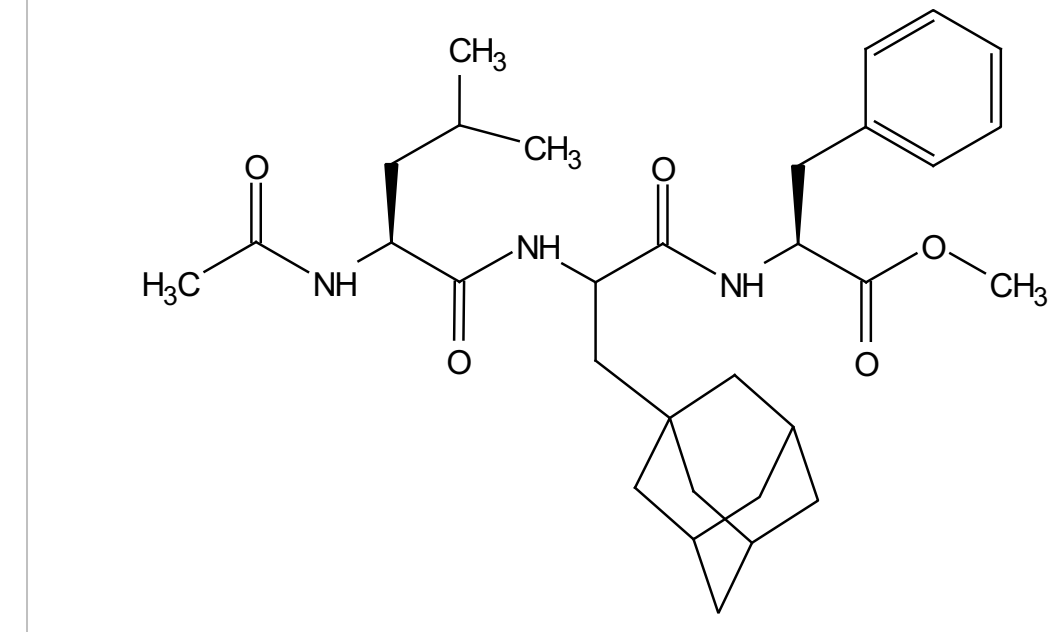

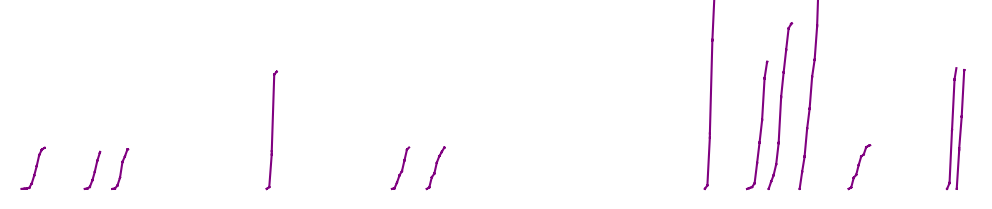

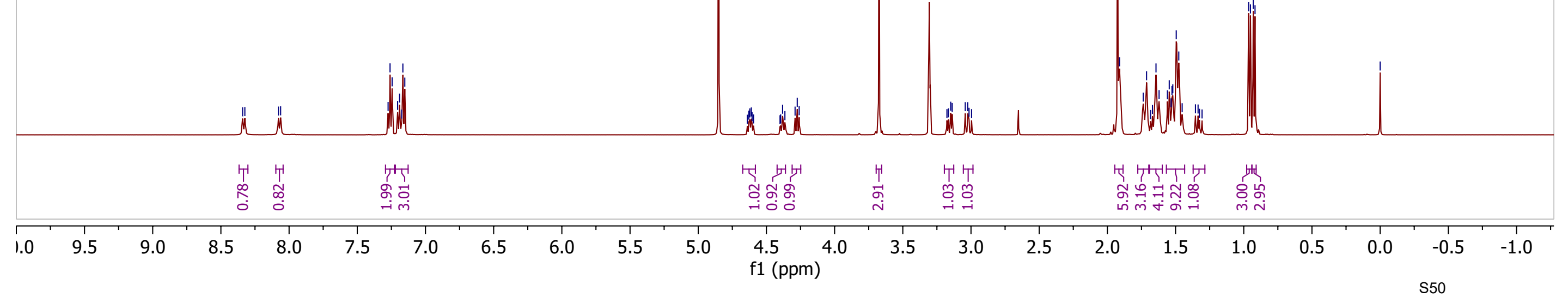




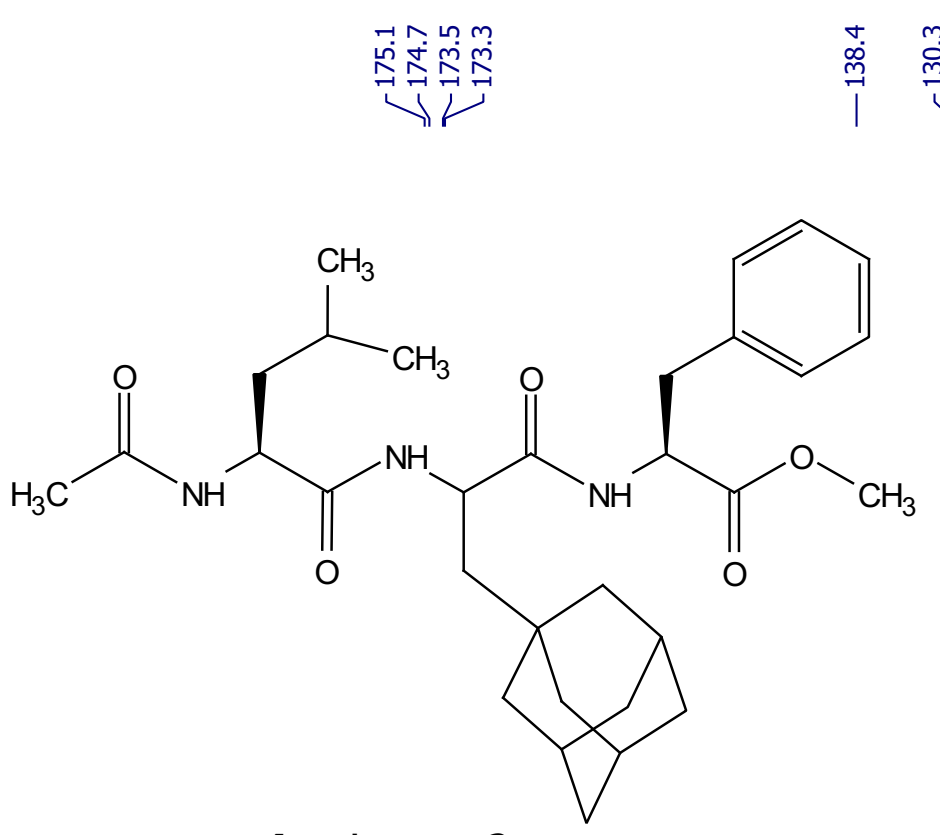

4c - isomer 2

$126 \mathrm{MHz}, \mathrm{CD}_{3} \mathrm{OD}$

\begin{tabular}{|c|c|c|c|c|c|c|c|c|c|c|c|c|c|c|c|c|c|c|c|c|c|c|c|}
\hline :20 & 210 & 200 & 190 & 180 & 170 & 160 & 150 & 140 & 130 & 120 & 110 & $\begin{array}{c}100 \\
\mathrm{f} 1(\mathrm{ppm})\end{array}$ & 90 & 80 & 70 & 60 & 50 & 40 & 30 & 20 & 10 & $\begin{array}{r}0 \\
\text { S51 }\end{array}$ & -10 \\
\hline
\end{tabular}

